\title{
Tracing the Origins of Glioblastoma by Investigating the Role of Gliogenic and Related Neurogenic Genes/Signaling Pathways in GBM Development: A Systematic Review
}

Ovais Shafi ( $\square$ dr.ovaisshafi@gmail.com )

Dow University of Health Sciences

Ghazia Siddiqui

Jinnah Sindh Medical University

\section{Research Article}

Keywords: Glioblastoma, gliogenesis, aging, neurogenesis, glioblastoma origins, inflammation, cancer, oncogenesis, stem cells, regeneration.

Posted Date: January 25th, 2022

DOI: https://doi.org/10.21203/rs.3.rs-1208118/v2

License: (9) This work is licensed under a Creative Commons Attribution 4.0 International License.

Read Full License 


\section{Abstract}

Background: Glioblastoma is one of the most aggressive tumors. The etiology and the factors determining its onset are not yet entirely known. This study investigates the origins of GBM and for this purpose it focuses primarily on developmental gliogenic processes. It also focuses on impact of the related neurogenic developmental processes in glioblastoma oncogenesis. It also addresses why glial cells are at more risk of tumor development compared to neurons.

Methods: Databases including PubMed, MEDLINE and Google Scholar were searched for published articles without any date restrictions, involving glioblastoma, gliogenesis, neurogenesis, stemness, neural stem cells, gliogenic signaling and pathways, neurogenic signaling and pathways, astrocytogenic genes.

Results: The origin of GBM is dependent on dysregulation in multiple genes and pathways that accumulatively converge the cells towards oncogenesis. There are multiple layers of steps in glioblastoma oncogenesis including the failure of cell fate specific genes to keep the cells differentiated in their specific cell type such as p300, BMP, HOPX, NRSF/REST and others. There are genes and signaling pathways that are involved in differentiation and also contribute to GBM such as FGFR3, JAKSTAT, hey 1 and others. The genes that contribute to differentiation processes but also contribute to stemness in GBM include notch, Sox9, Sox4, c-myc gene overrides p300 and then GFAP, leading to upregulation of nestin, $\mathrm{SHH}, \mathrm{NF}-\mathrm{kB}$ and others. GBM mutations pathologically impact the cell circuitry such as the interaction between Sox2 and JAK-STAT pathway, resulting in GBM development and progression.

Conclusion: Glioblastoma originates when the gene expression of key gliogenic genes and signaling pathways become dysregulated. This study identifies key gliogenic genes having the ability to control oncogenesis in glioblastoma cells, including p300, BMP, PAX6, HOPX, NRSF/REST, LIF, TGF beta. It also identifies key neurogenic genes having the ability to control oncogenesis including PAX6, neurogenins including Ngn1, NeuroD1, NeuroD4, Numb, NKX6-1 Ebf, Myt1, ASCL1 and others. This study also postulates how aging contributes to the onset of glioblastoma by dysregulating the gene expression of NF-KB, REST/NRSF, ERK, AKT, EGFR and others.

\section{Background:}

The etiology and origins of Glioblastoma (GBM) are still unknown. GBM is unique in many ways as $90 \%$ of the times it occurs as primary tumor and $10 \%$ of the times as secondary tumor. It is more common in elderly population. The development of GBM is considered to be very complex in nature. Despite the fact that multiple genes and signaling pathways have been identified, still the origins of GBM remain largely unknown [1].

Neural Stem Cells (NSCs) are progenitors of both neurons and glial cells but the risk of tumor development is entirely different in both cell types. Glial cells are considered to be more involved in one of the most aggressive CNS tumor i.e. GBM but there are comparatively very few tumors of neuronal origin. 
It is important to note that medulloblastoma which is considered to be tumor of neuronal origin, it is mostly found in children but some cases are also found in adults till age 40. Neurons remain largely free of tumors of neuronal origin, but glial cells including astrocytes are at risk of tumor development such as GBM $[2,3][163]$.

The task of this study is to trace the origins of GBM. This study investigates GBM using the developmental biology of glial cells, alsoby focusing on related neurogenic genes/signaling pathways in glioblastoma oncogenesis.In the light of the findings of this study, it goes on further to postulate in the 'discussion' sectionthe likely reasons why glial cells are more predisposed to oncogenesis compared to neuronal cells. This study also investigatesthe related aspects of gliogenesis and neurogenesis to further investigate the origins of GBM.

\section{Methods:}

PUBMED database, MEDLINE database, Google Scholar and online journals such as BMC, PLOS, Cancer Cell, Neoplasia and others were searched with no date restrictions for published articles in relation to 'glioblastoma', 'gliogenesis', 'neurogenesis', 'neural stem cells'. It also sheds light on the genetic heterogeneity in GBM development.

Keywords used to investigate origins of glioblastoma: gliogenesis, gliogenic genes and signaling pathways, neurogenesis, neurogenic genes and signaling pathways.

The following gliogenic genes and signaling pathways were investigated for their role in glioblastoma oncogenesis:

IL-6 family, FGFR3, JAK-STAT signaling, BMPs, Notch signaling, Notch effector protein NFIA, SOX9, SOX4, STAT3, GFAP and S100, BMP with SMAD, p300/CBP, Notch/hey1, HES genes interactions between STAT3 and JAK 2, SHH, PAX6 with Nkx6.1, NF-KB signaling and inflammation in gliogenesis and GBM, Neuregulin-1, Neuronal restrictive silencing factor (NRSF)/ REST, MAPK, MEK, TGF beta, E2F, TCFL2, p130 with JAK STAT, Transcription factors NFIC and HOPX, Ephrins (EFNB1) and Netrins (NTN).

The following related neurogenic genes and signaling pathways were investigated for their role in glioblastoma oncogenesis:

Ngn1, NeuroD transcription factor, PDGF and Neurotrophin-3, CNS neural progenitor markers ( $P a x 7, D b x 2$, Nkx6.1, FGF), neurogenin-mediated neurogenesis (Ebf2,3, Hes6, Myt1, Neurod1, Neurod4, and Runx1t1), PAX6, BMP in neuronal development, NUMB gene, ASCL1, klf4, c-myc, SOX4, SOX2 induces ASCL1 and TLX TF, wnt signaling, Notch/STAT3-Ser/Hes3 Axis, GSK3 beta.

Only those articles were eligible to be included in this study on glioblastoma which were related to gliogenic genes and signaling pathways, key genes involved in neurogenesis specifically focusing on neuronal differentiation and also contribute to glioblastoma oncogenesis.Screening of the literature was also done on the same basis and related data was extracted.

Literature search began in November 2018 and ended in February 2021. During revision, further literature was searched and referenced until November 2021. 
The literature search and all sections of the manuscript were checked multiple times during the months of revision (March 2021 - November 2021) to maintain the highest accuracy possible. The prime focus of the literature search was to screen the literature on the basis of eligibility criteria mentioned above. Publications only in 'English' were used and there was no limitation on date of publication. Data extraction was based on these eligibility criteria. No unpublished study was used or included. This study adheres to relevant PRISMAguidelines (Preferred Reporting Items for Systematic Reviews and MetaAnalyses).

\section{Results:}

A total of 3810articles were identified using database searching, 3494 were recorded after duplicates removal. Three thousand sixty-six (3066) were excluded after screening of title/abstract, 202 were finally excluded (because when many separate articles were present with similar conclusions, only those were selected to be included which mainly focused on genes/ signaling pathways involved in gliogenesis and neurogenesis in relation to GBM development), 3 articles were excluded during data extraction.Finally 223 articles were included (based on the objectives of the study).

There are also limitations of this study as mentioned in the 'Methodology' 'Study Design' and other respective sections. The TP53, RB1, MDM2, NF1 or other such factors that already have well established role in glioblastoma development [4], they are not the primary focus of this study.

Based on the results of this study, it also addresses in the 'Discussion' section the increased predisposition of glial cells towards oncogenesis compared to neurons. This will help to understand the factors that put the glial cells such as astrocytes more towards at risk of oncogenesis such as glioblastoma development.

This study investigates the gliogenic genes and signaling pathways to trace the origins of GBM, it also focuses on related neurogenic genes/signaling pathways that play role in GBM oncogenesis. It focuses on the signaling pathways and genes that work in the form of combinatorial codes in cell type specific programming in gliogenesis and neurogenesis. This study also tries to map the landscape of genetic switches that lead to the origin of Glioblastoma, also illustrated in Fig. 1 (landscape of GBM onset and development).

\section{GLIOGENIC GENES/SIGNALING PATHWAYS AND THEIR ROLE IN GLIOBLASTOMA DEVELOPMENT:}

Key gliogenic genes having the ability to control oncogenesis in glioblastoma cells: p300, BMP, PAX6, HOPX, NRSF/REST, LIF, TGF beta.

- TGF beta: It has very important gliogenic effect. TGF beta family also includes BMP. The SMADS working with TGF beta, they inhibit G1 to $S$ transitions and cause cytostasis. They also inhibit Myc $[45][92,93,94,95,96]$.

BMP: BMP-mediated PS-SMAD1/5/8 plays significant gliogenic role. BMPs switch the progenitor cells towards gliogenesis. It also downregulates the gene expression of EGFR. The CTNF, BMP and JAK-STAT mediated astroglial differentiation is disrupted in GBM development. The role of BMP signaling is anti-oncogenic as it causes the cell cycle to exit. CTNF and BMP dysregulations have 
downstream effects [29, 30]. It inhibits proliferation in GBM but stemness remains intact [31]. Several studies have found that BMP signaling has cell-differentiation effect in GBM [32]. BMP also works with STAT3 for astroglial differentiation. This regulation of STAT3 is very crucial as STAT3 overactivation is involved in GBM oncogenesis [33].

BMP with SMAD proteins: They contribute to gliogenesis in CNS development. The SMAD/TGF-beta together regulates the cell cycle and cause cytostasis by downregulating gene expression of c-Myc. This prevents $G 1$ to $S$ transitions [45]. The importance of dysregulations in the regulators of cell cycle can also be best estimated by the fact that SMAD/TGF beta becomes oncogenic in GBM and fails to prevent $G 1$ to $S$ phase transition. The dysregulations in SMAD alters role of PDGF-B in GBM development. When Smad, PI3K and FoxG1 signaling pathways are dysregulated, they switch the TGF-beta to become oncogenic [46]. EGFR-Akt-Smad signaling is also another way via which SMAD contributes to GBM development. TGF- $\beta 1$ works with Smad, p38 MAPK, and PI3K/Akt signaling pathways in GBM development [47]. TGF beta interacts with VEGF and FGF. This process is negatively regulated by $\mathrm{PI} 3 \mathrm{~K}$ pathway which is an inhibitor of FoxO localization in the nucleus. $\mathrm{PI} 3 \mathrm{~K}$ also becomes dysregulated in GBM development [48].

- PAX6 is neurogenic in development but with Nkx6.1 it contributes to astrocytogenesis: PAX6 role is fascinating at many levels as it controls the cell proliferation and also plays role in regulating the cell cycle. There is inverse relationship of PAX6 with GBM development. When PAX6 is upregulated in GBM, it acts as a tumor suppressor $[67,68]$. It is the combinatorial effect of multiple genesworking at specific timings that regulate the establishment and homeostasis of the cell fate. PAX6 is primarily neurogenic and works with Nkx6.1 in establishing some types of astrocytes [69]. PAX6 also suppresses the invasiveness of GBM and controls the expression of matrix metalloproteinase-2 gene [70]. PAX6 also controls the VEGF expression in GBM and prevents angiogenesis. It stops the cells from entering S-phase of cell cycle and also induces apoptosis. It also interacts with PTEN signaling pathways [71]. The transcription factor PAX6 exerts a very strong neurogenic role. It has been proposed to be a regulator of balance between astrocytes and other glial cells [72]. PAX6 also interacts with neurogenins to swing the stem cells towards neuronal commitment state.

In a 2018 study, CRISPR-CAs9 was used to study the role of PAX6 in GBM development. PAX6 has very strong neurogenic role and its expression has been found to work as tumor suppressor gene in GBM. The role of PAX6 is also pleiotropic in nature. Its signaling is involved in the differentiation processand is also capable of exertingimpact on GBM oncogenesis [73]. Pax6 interacts with regulators of neural progenitor cells including Neurod1/4, Nestin, Neurog1/2, and Notch pathway components such as DII1 and Hes6 [74].

It is very important to note that neuronal cells are the cell types with the least risk of tumor development while glial cells are most likely the cell types in which one of the most aggressive tumors originates, GBM. It is postulated here that there are many genes whose expression may provide a different effect in different cell types. This variability may have origin in cell fate specification based on the differentiation of cell types, such as PAX6 plays different roles in neurons and astrocytes. This is also evident in different disease states such as in Alzheimer's disease and 
glioblastoma, in both diseasesthe genes such as p53 have different roles. In Alzheimer's diseases p53 is upregulated while in GBM it is downregulated. PAX6 and Sox2 are involved in gene regulation of neural stem cells in neurogenesis. Both are also contributors in the commitment of ectodermal cells towards neuronal differentiation. Their contributions also go to the extent of inducing transcription factors that contribute to neurogenesis. They work in the form of gene regulatory circuitry. PAX6 is deeply interlinked with notch signaling in inducing neurogenesis. It is not properly understood yet the level of complexity with which they work together. One of their key roles that are of immense significance is the repression of non-neuronal cell types.

- P300/CBP:

$P 300$ is a very strong regulator of gliogenesis. It is also the repressor of nestin which is also involved with stemness (sox2). Its activation in GBM cell lines induces the cells more towards GFAP expression. The impact of $\mathrm{P} 300$ on the cell fate can be estimated from this fact. It is important to note here that c-myc gene overrides $p 300$ and then GFAP, leading to upregulation of nestin. This plays very important role in GBM oncogenesis [49].

\section{- Neuronal Restrictive Silencing Factor (NRSF)/REST:}

It halts neurogenesis and inducesgliogenesis. Initially it was considered to function only to repress neuronal genes in non-neuronal cells. Now its presence in many different cell types has emerged. It is expressed in neural progenitor cells (NPCs) but negatively regulates neurogenesis. It has also been found to be involved in many cancers [83]. It is considered to be contributory towards the neurodegeneration in Alzheimer's disease as it is downregulated in Alzheimer's disease neurons. It has been found that REST remains in quiescent state in differentiated neurons but its expression increases after neuronal injury. With aging, there is always present low level of REST gene expression in the neurons because its absence may fuel Alzheimer's disease. REST also reduces beta amyloid toxicity and apoptotic signaling [84]. In GBM, it contributes to more invasive and proliferative properties of GBM. It also contributes to renewal of GBM stem cells and is oncogenic in GBM landscape [85].

REST amplification is also implicated in GBM and has been found to suppress apoptosis in GBM cells. It also promotes stemness in GBM. Though NRSF/REST is considered to have more profound role in gliogenesis but in medulloblastoma where neuronal pathways are involved, its overexpression has been detected as it is linked to enhancing proliferative capabilities. REST based stemness has been detected in both neuronal tumors such as medulloblastoma and glial tumors such as GBM. REST also interacts with shh, wnt and PI3K signaling pathways. All of them have wellestablished role in GBM oncogenesis. In adult neurons, the gene expression of REST remains low so as to promote the gene expression of neuron specific genes which REST can downregulate. But REST is upregulated many folds in medulloblastoma cells, the role of REST overexpression is very important as blocking the REST gene expression results in revival of neuronal genes and also promotes apoptosis [86]. REST overexpression is also part of GBM. It also provides a key finding about pro-neural type of GBM as when P53 and REST are deleted; it switches the cells to change into pro-neural type of GBM [87]. REST in normal cells contributes to genomic integrity, but in cancer development it is oncogenic. It also contributes to invasion, stemness and also regulates apoptosis 
[88]. NRSF/REST is highly upregulated in NSCs to maintain stemness and prevent neuronal differentiation. Its gene expression downregulation contributes to drive the neuronal differentiation. But after neuronal differentiation, a basal level of NRSF/REST expression is maintained all the life and increases with aging. There is aging related increase in REST expression in brain cells including neurons and astrocytes. REST has strong interactions with WNT signaling pathways and both have significant oncogenic role in GBM. It also downregulates the genes involved in apoptosis [89]. The differences in REST gene expression are likely one of the key reasons of different proliferative potentials between two cell types, i.e. neurons and glial cells. It is postulated here that as REST is gliogenic and is not similarly expressed in neuronal cells which are considered permanent cells, hence the direction of cell circuitry guided by REST tends to have high proliferative potential. The REST based proliferative potential is so strong that it is also involved in tumor development in neuronal cell type (medulloblastoma) by silencing the key neuronal cell type specific genes. NRSF/REST works as one complex developmental expression program. It has been found to be highly expressed in almost all non-neuronal cells. Hence, it is also considered to be a master regulator of transcription. One of its most significant roles is to regulate gene networks that are involved in maintaining pluripotency in embryonic stem cells.

- Leukemia inhibitor factor (LIF): Normally it inhibits differentiation but its low levels cause differentiation. In GBM, TGF-beta signaling causes it to become pro-oncogenic. Although when LIF is applied alone to cell lines, it causes growth inhibition in GBM [9].

Genes that have gliogenic roles but in GBM development contribute to the oncogenesis: IL-6 family, FGFR 3, JAK-STAT pathway, STAT3, S100, hey1, HES1, DTX, NF-KB, Neuregulin-1, MAPK, MEK, E2F, TCFL2, NFIX TF, Ephrins (EFNB1) and Netrins (NTN).

- FGFR signaling pathway: FGFR3 is one of the mitogenic drivers in GBM development. It also contributes to further driver mutations. In GBM disease development, it activates very crucial pathways such as AKT, Ras-Raf-MEK-ERK pathway [10]. FGFR signaling pathway is profoundly involved in cancers including brain cancer such as GBM [11]. In GBM, their role is complex and is based on their ability to contribute towards glial differentiation. FGFR signaling pathway has strong interactions with MAPK which is involved in gliogenesis and also in GBM development. FGFR2 is involved in gliogenic differentiation, its activation in glioma cells causes differentiation of brain glioma cells [12]. FGFR 1 and 2 are expressed in neurons and astrocytes respectively. Their expression decreases with grade of glioma $[13,14,15]$. It is important to mention here that IGF-1, FGF, PDGF and EGF, all are based on receptor tyrosine kinase and they all have significant roles in GBM development. FGFswitches NSCs towards glial fate in embryogenesis. The cell fate based switching is through MAPK pathway. FGF is also involved in GBM. FGF also works with IGF to regulate MAPK pathway. The role of IGF-1 in cancer development is well established. IGFR signaling pathway interacts with AKT to further GBM proliferation [91].

- JAK-STAT pathway: It is a key gliogenic pathway. It interacts with PI3K/AKT/mTOR Pathway. It has ability to integrate with MAPK/ERK pathway. There are negative regulators that keep JAK-STAT in 
check such as tumor suppressor genes. In GBM, JAK-STAT becomes oncogenic. It also contributes to the stem cell maintenance. The JAK-STAT pathway downstream targets include Bcl-xL, Bcl-2, cyclin D1, and c-Myc, and EGFR amplification which lead to further dysregulated STAT3 signaling. Dysregulated EGFR, FGF, PDGF, C-MET, also activate STAT-3 signaling. The EGFR based negative regulatory mechanisms become dysregulated in $\operatorname{GBM}[16,17]$. The dysregulations in JAK/STAT signaling lead to upregulation of pluripotency related genes including oct4, c-Myc, Nanog, Sox2 [18, $19,20,21,22]$. Sox2 is also involved with JAK-STAT signaling pathway in maintaining pluripotency. TGF Beta, SMAD, and IL6 family also interact significantly with JAK-STAT pathway $[23,24,25,26,27$, 28].Damage to RB2/p130 diminishes its tumor suppressor effect and contributes to GBM progression [103].

\section{- STAT3:}

The role of JAK-STAT pathway and STAT3 is well established in gliogenesis. Oncogenic mutations also dictate the role of STAT3 in relation to its interactions such as with PTEN-Akt-FOXO axis (suppressive) and with Leukemia inhibitory factor receptor beta (oncogenic). It also interacts with EGFR which plays key role in GBM development $[42,43]$. The knockdown of STAT3 or SRF significantly suppressestumor invasive properties. It also interacts with HOPX which is gliogenic and also expresses tumor suppressive effects [97].

It is postulated here that genes and pathways including STAT3 have multiple biological roles which are also guided by the timing and gene expression of other factors that regulate the cell cycle. In tumor microenvironment, a physiologic pathway may go on to become oncogenic. Their integrated relationship with one another decides the maintenance of cell fate or deviation of cells from their cell fate.

- IL- 6 family: In GBM, it works with STAT3 in promoting pro-oncogenic pathways [5]. It is to note that cytokines IL-2, IL-6, IFN, all involve JAK-STAT based non-receptor tyrosine kinase signaling. With age, the gene expression of inflammatory cytokines increase in the body. In GBM, CTNF and its receptor have been found in GBM [6].

CTNFR alpha is pro-glioma and is linked to the grade of glioma. It is considered to have role in initiation or GBM maintenance [7, 8]. CNTF-mediated JAK-STAT pathway contributes to astrocytogenesis as well.

- GFAPand S100:

They are involved in astrocytogenesis and are also upregulated in GBM, indicating the cell type specific contributions to GBM development. GFAP also regulate astrocyte neuronal interactions [44].

\section{- Notch targets Hey1:}

One of the key targets of Notch signaling is Hey 1 and this is also upregulated in GBM. Notch signaling in later stages stimulates gliogenesis $[50,51,52,53]$. It is postulated here the timings of gene activity and microenvironment impact profoundly in the process of maintaining cellular homeostasis and in disease development. The dysregulations in gene expression of Notch also induce profound impact on the genes it regulates and the pathological effect goes further in downstream pathways. 
- Interactions of Hes1 with STAT3 and JAK2:

These interactions play very important role in gliogenic developmental mechanisms. But dysregulated expression of even the key genes including Notch1, Hes1, and DTX1 contributes to GBM pathogenesis $[54,55,56]$. Dysregulated Hes 1 plays role in stemness and EMT induction in GBM development. Shh also upregulates Hes1 gene expression [57]. SHH will be discussed later. In understanding GBM, it is of immense significance to understand interconnectedness of signaling pathways and genes. The interactions of Notch are very diverse as it also interacts with Hes3 signaling axis and STAT3, and plays physiologic role of being the regulator of Neural Progenitor Cells (NPCS). In GBM, Notch, STAT3, Hes3 axis all become dysregulated.

\section{- NF-KB harms neural stem cells (NSCs) and gliogenesis potential:}

The role of inflammation in GBM oncogenesis and its impact on the GBM genetic landscape is of immense significance. It is already well established that the levels of inflammation in body increases with aging. NF-KB which also acts as one of the prime regulators of inflammation, it gets upregulated. And NF-KB has been found to play very important role in GBM oncogenesis as it also plays role in EGFR amplification. The EGFR amplifications also contribute to the pyruvate kinase $\mathrm{m} 2$ (PKM2) dysregulations, resulting in the upregulation of this rate limiting enzyme of glycolysis in GBM. In GBM, NF-KB and EGFR interactions contribute to GBM development, invasiveness and progression [75].

There is also depletion of negative regulators of NF-KB such as KLF6. The upregulation of NF-KB in GBM also contributes to Epithelial Mesenchymal Transition (EMT) and GBM stemness. The NF-KB is linked with TNF alpha and IL1 expression. It interacts with MAPK, Tyrosine Kinase-R, EFGR, PDGF and AKt signaling pathways. They are also part of GBM landscape. The NF-KB signaling promotes IL-6, IL-8 and VEGF, further fueling GBM development. It also interacts with PI3K/AKT pathway. With loss of PTEN and NF1 which are well established contributors to GBM development, the PI3K/AKT becomes upregulated. Similarly like other tumor suppressors such as PTEN, NF1 and others, also loss of P53 contributes to GBM oncogenesis. The dysregulations in P53 also contribute to NF-KB upregulations. NF-KB also interacts with cascades of genes that are involved in cell survival including $B c l-x L, B c / 2$, inhibitor of apoptosis proteins and survivin,cyclin D1 and others. The NF-KB in GBM has strong interactions with EFGR, PDGFR and AKT signaling pathways. The loss of tumor suppressor in NF1 also causes RAS over-activation [76]. PTEN regulates PI3k and blocks AKT signaling. The dysregulations in P53 also contribute to Mdm amplifications in GBM oncogenesis. The NF-KB also disrupts the notch signaling and promotes the cell signaling through cell proliferation with CyclinD1 [77].

It is important to note here that NF-KB signaling upregulation is also involved with loss of tumor suppressors. It is also postulated here that inflammatory signaling cascades have more profound role in GBM oncogenesis than previously assumed. As aging also increases inflammation and most cases of GBM have onset with increased age, hence role of aging is of immense significance in GBM development.

- Neuregulin-1 is a gene of EGF family and contributes to astrocytogenesis:

Nrg1 and erb receptor signaling pathways interact with each other and also with PI3K, contributing to Page 9/55 
the growth of GBM. The role of EGFR amplification is already well established in GBM $[78,79,80$, 81]. Nrg1, TGF alpha, EGFR all have profound interactions with one another and impact PI3k/AKT pathway, MAPK and JAK/STAT pathway [82].

It is postulated here that Nrg1 is very significant in GBM landscape as it is involved in astrocytogenesis during embryonic development but in GBM landscape, it becomes oncogenic. It signifies the role of cell fate specific genetic programming that regulates the unique gene transcripts in a specific manner. In GBM, when dysregulations in signaling pathways and genes accumulate beyond a specific threshold then the role of many factors such as Nrg1 may become dysregulated. This further fuels GBM development and progression. The FGFR3 has major gliogenic contributions, but in GBM development it also loses the cell fate specification related effects. As the cell fate is determined by combinatorial code based specific unique set of gene programming, this loss of cell type specific gene expression is able to swing FGFR3 towards becoming oncogenic.

- MAPK: In GBM, it interacts with EGFR, mTOR/PI3K/Akt and RAS. It also works with PDGFR. MAPK is also involved In Insulin resistance. The pathway mTOR stimulates glucose uptake in GBM and works with Akt pathway[90].

- MEK and E2F: RAS over-expresses MEK in GBM. Rb1 interacts with CDKs in inhibiting E2F. This pathway becomes damaged in GBM and CDKs cause E2F based $\mathrm{G} 1$ to $S$ transitions $[98,99]$.

- TCFL2: TCF/LEF transcription factors of WNT signaling works with beta catenin and have been detected in GBM samples [100, 101, 102].

- Ephrins (EFNB1) and Netrins (NTN): These pathways related proteins are involved in gliogenesis. Their role also includes angiogenic activity including angiopoietin-2 (ANGPT2), EFNB1 and FGF. The dysregulations in Ephs and Ephrins are involved in GBM development. Their downstream signaling includes MAPK, ERK, RAS, AK, FGF, MEK, PI3k/Akt/mTOR and others [108].

Netrins over-expression contributes to the increased proliferation of GBM cell lines. It is also involved in gain of stemness in GBM. NTN-1 activates Notch signaling in GBM and contributes to oncogenesis. This increases the expression of CD133, nestin and Sox2 in GBM stem cells [109]. Netrins also interact with EGFR. This reduces partially the GBM cell senescence that occurs from DNA damage. This EGFR based role is mediated by AKT and ERK signaling pathways.

- Transcription factors NFIX and HOPX with GFP control: This is involved in gliogenesis and is dysregulated in GBM.

NFIX TF interacts with STAT3 and has been found to be upregulated in GBM. NFIX works with Ezrin protein that is involved in cross-linking of cytoskeleton and plasma membrane; both are dysregulated in GBM [104].

HOPX is primarily astrocytogenic and also works as tumor suppressor in time dependent manner. HOPX is also involved in neural stem cells and is downregulated in solid tumors. This downregulation promotes tumor invasiveness and growth. It is important to note that HOPX overexpression is involved in suppression of cancer cell proliferation and metastasis. Key genes of interest with which HOPX interacts include ASCL2, NKX2-1. HOPX contributes to regulation of $\mathrm{NOTCH}$ and also causes senescence by activating Ras and MAPK pathway. It is also involved in 
upregulating klf4 in promoting tissue homeostasis. Klf4 is involved in pluripotency and time dependent switching of astrocytes into neurons. It also regulates apoptosis in stem cells. When it becomes dysfunctional, stem cell apoptosis decreases and more neurons are produced. Its upregulated gene expression promotes apoptosis. HOPX also contributes to neurogenesis by modulating NOTCH pathway signaling but it plays more profound role in gliogenesis [105]. It is postulated here that role of HOPX is far different than other gliogenic factors that become oncogenic when dysregulated including Notch, FGFR3 and others. Its effect on cancer cells is tumor suppressive. It keeps NSCs in quiescent stage, also regulates proliferation and differentiation [106]. GBM lacks expression of HOPX and its induced expression causes tumor suppressor effect in many GBM cell lines by decreasing survival but proliferation remains unaffected [107].

Key genes that contribute to gliogenesis but also contribute to the stemness in GBM: Notch (cancer stem cells), Sox9, Sox4, SHH.

- Notch signaling pathway: In gliogenesis, Notch effector protein (NIFA) binds to GFAP promotor and contributes to astrocytogenesis. EGF motifs and notch signaling are interlinked. In GBM, EGFR amplifications are one of the most significant parts of GBM oncogenesis. GBM cells also have presence of cancer stem cells [34]. Notch2 expression is involved with proliferating cells that function as progenitors. Notch1 gene expression is involved in post-mitotic cells that are in differentiated state. In GBM, Notch1 promotes Akt signaling, also causes $\beta$-catenin and NF-KB upregulation. In GBM, Notch2 is also upregulated but contributes to GBM stemness. Notch signaling pathway also interacts with stemness genes (nestin, SOX2), with vimentinand GFAP that are involved in astrocyte fate. It also inhibits apoptosis [35]. Dlls are linked with Notch signaling. They are upregulated in GBM and contribute to oncogenesis $[124,125,126]$. Nestin upregulation contributes to GBM stem cells $[127,128,129]$.

Notch signaling is regulator of EGFR and EGFR amplifications are also modulated by dysregulations in TP53. Notch signaling and EGFR, both are upregulated in GBM oncogenesis. Importance of notch signaling in developmental mechanisms and its impact on GBM development both are very significant part of GBM research. They both work like a positive feedback signaling loop. EGFR interacts with RAS-RAF-MEK-ERK and the PI3K-AKT-mTOR cascades.It also interacts with CDKs. Inhibition of notch also promotes apoptosis in GBM cells. Notch inhibition also decreases gene expression of Akt and Stat3. Delta/Notch-like epidermal growth factor-related receptor (DNER) is involved in GBM progression. The notch signaling pathway also regulates neural stem cells (NSCs). Though Notch is also involved in cell fate decisions in gliogenesis but in GBM microenvironment, it makes tumor cells more invasive and increases de-differentiation. Higher grade of gliomas have been linked with increased gene expression of ASCL1, DII1, notch1, notch3, notch4, and hey1. The ASCL1 is also used as a transcription factor in the switching of astrocytes to neurons. Dysregulated Notch also interacts with other important developmental genes and gene expression levels of Notch1, Notch4, DII1, DII4, Jagged1, CBF1, Hey1, Hey2 and Hes1 are upregulated in GBM oncogenesis. There is also simultaneous decrease in PTEN expression, resulting in upregulation of Akt and VEGF. The notch mediates overexpression of genes including Zeb1, and Snail, vimentin. This 
enhances invasiveness of GBM. The notch signaling also interacts with Hey1, PI3K/AKT/mTOR and ERK/MAPK pathway. All of them also act as proliferative and survival signaling [36]. Hey 1 enhances GBM survival and interacts with dysregulated Notch and E2F signaling. It is considered that the notch signaling is one of those key pathways whose inhibition can promote GBM cells to differentiate and promote apoptosis. Despite having such crucial role, still inhibition of notch signaling pathway doesn't reverse GBM oncogenesis [37]. Notch signaling is an important player in gliogenesis. The oncogenic alterations in notch signaling pathway sets in motion a cascade of pathological downstream dysregulation such as hey 1 gene which interacts and works with notch signaling, its gene expression is increased in GBM development [38].

NOTCH works with FGF to keep NSCs in proliferative stage. Neural progenitor cells (NPCs) are regulated by notch signaling, it is also involved in their maintenance and renewal. But later in developmental, NOTCH contributes to glial cell differentiation.

\section{- SOX9 and SOX4:}

It is involved in gliogenesis. The pathways Shh and Notch use Sox9 as regulator of morphogenesis. It also works with SOX10 for maintenance multi-potency of neural crest cells. It also differentiates NSCs into non-neuronal cells. Sox9 upregulation contributes to oncogenesis in GBM and interacts with wnt/beta catenin for progression of GBM. Knockdown of Sox9 in GBM impairs the proliferation of glial cell types and cause apoptosis [39, 40]. Sox9 interacts with EGFR, BMI-1, PTEN. Other SOX including Sox5, Sox6, and Sox17 also contribute to GBM. SOX4 in Glioblastoma sustains stemness and is regulated by TGF- $\beta$. It also modulates SOX2. The SOX2 in glioblastoma maintains stemness and oncogenic properties. Sox members in GBM also interact with TGF beta and are involved in reprogramming of GBM stem cells [41].

It is postulated here that factors that swing the stem cells towards non-neuronal cell types which are not permanent in nature and have proliferative capacity, they are at risk of oncogenesis later in life. Many genes such as Sox 9 that are gliogenic in embryonic development, they may become contributor to GBM oncogenesis because of dysregulations in cell circuitry at the time of GBM development. Such dysregulations change the direction of cell fate and they become more and more undifferentiated. It is important to note that sox 9 and NIFA together work as regulator of key gliogenic genes in embryonic development. Their over-expression cause astrocytic differentiation in GBM cells. Many pathways that work in a combinatorial manner, they may get dysregulated with aging. Such dysregulations in cell circuitry lead to disease development such as GBM. The transcription factor NIFA, key initiator of gliogenesis works with Notch and Hes signaling pathway and pathological dysregulations in one key pathway lead to further downstream damage. It is further discussed in later parts of the study.

\section{- SHH:}

Astrocytogenesis is linked with inhibition of neurogenic signals in Neural Stem Cells (NSCs). While $\mathrm{SHH}$ is secreted by neurons and work more as a connecting bridge between neurons and glial cell. It works with Nkx2.2 in defining the identity of neural progenitor cells. But still it also contributes to the development of glial cells as well [58]. Sox9 is downstream effector of Notch and SHH. The role of $\mathrm{SHH}$ in GBM becomes more significant as Hes1 that is also involved in stemness of GBM, is also 
upregulated by $\mathrm{SHH}[59,60,61]$.

The role of PTEN is very significant as it also contributes towards controlling the SHH and PI3K expression. When PTEN becomes defective in GBM, then SHH and PI3K become dysregulated and both contribute to GBM oncogenesis [62].

$\mathrm{SHH}$ works as a morphogen but its sensitivity in neural cells is determined by BMPs. SHH have more profound role in neurogenesis compared to gliogenesis. $\mathrm{SHH}$ regulates and induces a variety of regulatory genes including 2, Olig2, Nkx6.1, Nkx6.2, Dbx1, Dbx2, Irx3, Pax6, and Pax7. This is mentioned here to show the far reaching impact of SHH dysregulation in GBM development. Cross talk of SHH with many key pathways and genes, play major role in regulating the activity of all of them. Such major interactions include GSK3 beta, mitogen activated protein kinase (Mek1), PKA and protein kinase $\mathrm{C}$ (PKC), Phosphoinositide-3 kinase (PI3K), CK1 or dual specificity Yak1-related kinase (DYRK1) and others. SHH is also modulated by these interactions. SHH also has major interactions with key signaling pathways including TGF-beta, wnt/beta catenin and notch.It also interacts with KRAS, PKA and EGFR. The signaling pathway SHH has profound regulatory interactions with GSK3 beta as it can act both as negative regulator and positive regulator of $\mathrm{SHH}$ depending on the microenvironment. Many major signaling pathways and key genes have regulatory interactions with shh, notch,wnt signaling, ERK signaling pathway, wnt/ $\beta$-catenin and KRAS, TGF- $\beta / T G F-\beta R$, EGFR, and platelet-derived growth factor receptor a (PDGFRa). In GBM development, their dysregulation plays key role in progression of the oncogenesis $[63,64]$.

EGFR that is considered to play key role in GBM development, its cross-talk with SHH in GBM further fuels oncogenesis. SHH dysregulations are capable of inducing the profound impact on the gene expression of EGFR/RAS/RAF/MEK/ERK in different cancer cell lines [65]. The EGFR signaling downregulates the gene expression of negative regulators of Shh signaling, further fueling cascade of downstream changes by impacting the gene expression of Akt, ERK and others [66]. It is postulated here that as cell fate is determined by unique combinations of transcription factors and regulatory genes. When such key genes and signaling pathways including SHH become dysregulated, the cells switch towards de-differentiation. This downstream cascade of damage works like a positive feedback loop that keeps switching the cells towards higher grade and more aggressiveness. There exists a very delicate balance among the expression of different genes which exert their effect on one another. For example, PTEN acts as tumor suppressor and it also impacts SHH and PI3K. When PTEN is damaged in GBM development, then it produces number of downstream pathological changes. The role of SHH in inducing and determining the cell fate is concentration and time dependent. The dysregulations in signaling pathways such as SHH in GBM landscape and development, they can set in motion a cascade of oncogenic changes. This cascade is based on the interactions of genes involved and their roles in cell circuitry. The negative and positive regulatory effects of genes and signaling pathways are of major significance as dysregulations in one can set in motion a cascade of pathologic changes. Such changes unfold step by step and in time dependent manner influenced by their microenvironment. 
RELATED NEUROGENIC GENES/SIGNALING PATHWAYS AND THEIR ROLE IN GBM ONCOGENESIS:

GBM cells maintain low or null expression of neurogenic genes. Here we investigate their significance in GBM [110].

Key neurogenic genes having the ability to control oncogenesis in Glioblastoma cells: PAX6,Neurogenins including Ngn1, NeuroD1, NeuroD4, Numb, NKX6-1 Ebf, Myt1, ASCL1.

- Neurogenins including Ngn1: It prevents the interaction between p300/CBP complex and STAT3, thus preventing gliogenesis and promoting neuronal differentiation. In GBM, its expression causes mitotic arrest [111, 112].

- NeuroD: It is also the most potent key regulator of neurogenesis and is involved in the differentiation of neuron. In GBM, its induced gene expression also blocks the proliferation. NeuroD1 is so potent that it is able to switch reactive glial cells into neurons. Key interactions include Cyclin D1, MAFA and MAP3K10.The NeuroD1 and NeuroD4 are key neurogenic pathways. Their upregulation cause arrest of cell cycle in GBM cells.

But the BDNF works in close association with NeuroD and activates the neurogenic SHP2-Ras-RafMEK-ERK pathway. This interferes with gliogenic JAK-STAT signaling. The neurogenic SHP2 is linked with potentiation of MEK-ERK signaling and inhibits gliogenic JAK-STAT signaling. In GBM, SHP2 becomes dysregulated and oncogenic [113].

- BMP in neuronal development:

It is involved primarily in the induction of neurogenin and ASCL1. The BMPS are involved in both gliogenesis and neurogenesis, but play a major role in switching NSCs towards astrocytogenesis. And its expression is also present postnatally in astrocytes. BMP upregulation is considered to play role in halting GBM progression [130, 131].

- PAX6: It is neurogenic but in GBM developmentits expression is like a tumor suppressor. It interacts with neurogenins to swing the neural stem cells towards neural commitment state and is involved in the repression of non-neuronal cell types. When weak Shh signaling combines with strong TGF-beta signaling, the PAX6 becomes upregulated. PAX6 expression is maintained in many areas of brain throughout life $[67,68][70]$.

- Numb gene negates Notch signaling and contributes to neuronal differentiation:

Upregulation of Numb gene contributes to halting the GBM growth and progression. It also upregulates the Pax6 and Sox2. It also interacts with EGFR. But the functions of Numb are so diverse and complex as it has also been found to be highly upregulated in mesenchymal GBM cells [132]. But this may be due to the fact that despite gene expression upregulation GBM oncogenesis is beyond the control of numb. But still its tumor suppressor role is controversial [133].

- Nkx6.1: Increasing evidence indicates that it suppresses tumor development and metastasis [117, 118].

- ASCL1: It is strongly neurogenic. In GBM, its expression causes cascade of downstream changes and switch the cells towards neuronal cell fate. It also suppresses oncogenesis in GBM cells [134]. 
- Ebf: its loss in GBM contributes to oncogenesis because EBF3 downregulates the gene expression of proliferation and survival related genes including cyclins, CDKs, Mcl-1 and Daxx. It also upregulates genes involved in cell cycle arrest including p21, p27 [119].

- Myt1: It is neurogenic transcriptions factor. In GBM, its expression is involved in downregulating proliferation [120].

Genes that have neurogenic roles but in GBM development contributes to oncogenesis: PDGF, NT3, Pax7, Dbx2, hes6, Runx1 and Runx2.

- PDGF and NT3: Both are neurogenic, but in GBM landscape they play oncogenic role [114].

- CNS neural progenitor markers:Pax7 and Dbx2 Pax7 becomes upregulated in GBM with PTEN deficiency [115] and high DBX2 in GBM is linked with low survival [116].

- Hes6: Upregulated in GBM [121].

- Runx1 and Runx2: In GBM, there role is oncogenic [122, 123].

Key genes that contribute to neurogenesis but also contribute to the stemness in GBM: $\mathrm{klf4}$, myc, oct2, sox4, TLF TF, wnt signaling, sox2, sox4, Notch/STAT3-Ser/Hes3 Axis, GSK3beta also works with $\mathrm{PI} 3 \mathrm{~K} / \mathrm{FGF}$ signaling pathway and contributes to stability of c-myc.

- Wnt signaling: It is kept in check by tumor suppressors and is more involved in neurogenesis. It is also involved in insulin based increase in glucose transporters. This increase is mediated by activation of wnt/beta catenin signaling pathway. It also plays role in diabetes type2 pathogenesis. In neurogenesis, wnt acts on Pax6-Ngn2-Tbr2-NeuroD-Tbr1 based neurogenesis TFs cascade. The wnt signaling represses astrogliogenesis via ngn2-dependent direct suppression of astrocyte gene expression. When wnt is inhibited, this promotes gliogenesis.Wnt1 works as antagonist of neural differentiation and promotes the proliferation of neural stem cells (NSCs).

But in GBM landscape, it becomes highly oncogenic. Cancer Stem cells are heavily associated with WNT signaling. Dysregulated wnt signaling causes activation of CyclinD1 and c-myc, causing G1 to $S$ phase transition. It also contributes to Epithelial to Mesenchymal transitions $[145,146,147]$.

\section{- GSK3:}

It has already been discussed in other sections too. Here we point out the integrated nature of GSK3beta interactions in normal cells and cancer cells. It also focuses on interconnectedness of beta catenin and GSK3-beta in development of GBM. The GSK3 and more specifically GSK3beta play a very significant role in normal cells and cancer cells. In normal cells, it acts as negative regulator of Epithelial-Mesenchymal-Transitions (EMTs) and many proto-oncogenes.But dysregulated GSK3beta is oncogenic [156].

Even in Alzheimer's diseases, it plays a very important role by forming a complex with p53 and contributes to neurodegeneration [157]. In developmental biology, GSK3 deletions contribute towards the enhanced proliferations of neural progenitor cells with simultaneous increase in SOX2 and beta- 
catenin expression. The GSK3 activation is involved in neuronal differentiation [158]. GSK3-beta has important interactions with beta-catenin which is capable of inhibiting neuronal differentiation. It also works with PI3K/FGF signaling pathway and contributes to the stability of c-Myc. In GBM, all of them become dysregulated [159]. In GBM, dysregulated GSK3-beta also acts to downregulate BMP that has significant gliogenic roles.It also downregulates CDKN1A and other important genes. GSK3 has interactions with many genes and pathways that are involved in GBM such as PI3k/AKT/mTOR pathway, wnt, notch, shh, ras, raf, mek, erk, APC, axin and others. It also interacts with key tumor suppressors including $p 53$, PTEN and others $[160,161]$. Though its main role is with neural progenitor cells and neurogenesis, but it is estimated that it may also have contributions towards gliogenesis [162].

There may be a possible relationship between GBM and diabetes type2. The GSK3 plays significant role in both the diseases. Inactivation of GSK3-Beta contributes to the insulin resistance. As astrocytes are glycogen storing cells and GSK3beta also has major association with PI3K/AKT pathway in diabetes type 2 and in GBM, this should be evaluated in great detail in future studies. This may point to some possible significance or relationship between diabetes type2 and GBM as the risk of both increases exponentially with age. Similarly, wnt signaling dysregulations have also been associated with diabetes type2. The MAPK, PI3K, AKT, mTOR and many other common genes/signaling pathways that are involved in disease development mechanisms of both GBM and Diabetes type 2, they should be investigated for any possible profound relationship. Investigating it any further is beyond the scope of this study.

- Myc: It is also involved in neurogenesis but is oncogenic in GBM development [136]. It is important to note here that myc gene overrides $p 300$ and then GFAP, leading to upregulation of nestin. This plays very important role in GBM oncogenesis [49]. GSK3beta also works with PI3K/FGF signaling pathway and contributes to stability of c-Myc.

\section{- Pluripotency in NSCs and brief look on their role in GBM: SOX2 and SOX4}

Sox 2 is associated with regulation and maintenance of neural stem cells. It becomes downregulated during later stages of differentiation. The role of Sox 2 in neurogenesis is very important because Sox2 also regulates the gene expression of other key genes. SOX2 induces ASCL1 and TLX TF. It alone is a very strong switch to neurons from astrocytes. In GBM, stemness is mediated by SOX2 and SOX4. They are also modulated by TGF-beta [148]. It also has several important key interactions with LIF signaling and KIf4. The dysregulations in both of them are also involved in development of GBM stem cells and invasiveness. The role of wnt signaling has already been explored in earlier sections of this study. Nanog, oct4, myc, they are also major contributors to GBM stemness [149].

- Klf4: Neurogenic but acts like oncogene in GBM [135].

- SOX2 induces TLX TF: TLX transcription factor works like an oncogene in GBM. It inhibits TGF-beta that causes cytostasis and this leads to the progression of oncogenesis [143, 144].

- Oct4: It is involved in pluripotency and stemness. Its expression is several fold upregulated in GBM. The FGF signaling pathway is involved in neuronal cell fate determination despite presence of oct-4 
gene expression. Without FGF signaling, the neural progenitor cell can revert back to embryonic stem cell like state with predominant oct-4 expression [137, 138, 139, 140, 141, 142].

\section{- Notch/STAT3-Ser/Hes3 Axis:}

This is neurogenic axis but it is linked to cancer development and diabetes. In GBM, it impacts the cascades of downstream signaling pathways. This signaling axis is important regulator of NSCs. Its major activators include insulin, Tie2 (involved in angiogenesis) and Notch. The upregulation of this axis has the ability to oppose the development of neurodegenerative diseases $[150,151,152,153$, 154, 155].

Hes3 has role of pro-survival signaling. It works with a strong relationship to SHH, and potentiates FGF and EGFR signaling. It is one of the key regulators with ability to reprogram cells into NSCs. In $G B M$, this signaling axis becomes severely dysregulated.

\section{SUMMARY:}

\section{GLIOGENIC GENES/SIGNALING PATHWAYS AND THEIR ROLE IN GLIOBLASTOMA DEVELOPMENT:}

- Key gliogenic genes having the ability to control oncogenesis in glioblastoma cells: p300, BMP, PAX6(Anti-GBM override), HOPX (tumor suppressive + differentiation), NRSF/REST (astrocytogenic but capable of playing oncogenic role), LIF, TGF beta.

- Genes that have gliogenic roles but in glioblastoma development contribute to the oncogenesis: IL-6, FGFR 3, JAK-STAT pathway, STAT3, S100, hey1, HES1, and DTX, NF-KB, Neuregulin-1, MAPK, MEK, E2F, TCFL2, NFIX TF, Ephrins (EFNB1) and Netrins (NTN)

- Key genes that contribute to gliogenesis but also contribute to stemness in GBM: Notch (cancer stem cells), Sox9, Sox4, SHH.

Note: Other stemness related genes such as nanog, oct4, FGF2 and others also get upregulated in GBM and contribute to the stemness in glioblastoma oncogenesis. But the prime focus of this study is to focus on key gliogenic and neurogenic genes/signaling pathways that are involved in cell fate maintenance and differentiation. This study focuses on investigating their role in GBM development and progression.

\section{RELATED NEUROGENIC GENES/SIGNALING PATHWAYS AND THEIR ROLE IN GBM ONCOGENESIS:}

- Key neurogenic genes having the ability to control oncogenesis in glioblastoma cells: PAX6, neurogenins including Ngn1, NeuroD1, NeuroD4, Numb, NKX6-1 Ebf, Myt1, ASCL1.

- Genes that have neurogenic roles but in GBM development contribute to the process of oncogenesis: PDGF, NT3, Pax7, Dbx2, hes6, Runx1 and Runx2.

- Key genes that contribute to neurogenesis but also contribute to the stemness in GBM: klf4, c-myc, oct2/4, TLF TF, wnt signaling, sox2, sox4, Notch/STAT3-Ser/Hes3 Axis, GSK3-beta works with PI3K/FGF signaling pathway and contributes to the stability of c-Myc. 


\section{GLIOBLASTOMA CORE PATHWAY ABNORMALITIES:}

Furthermore, glioblastomas are broadly divided into the following core pathway abnormalities. They are focused here to a limited extent because further focus is beyond the scope of this study.

1. RTK/RAS/PI3K signal alteration

\section{- Receptor Tyrosine Kinase in GBM and gliogenesis/neurogenesis:}

The most significant RTKs involved in glioblastoma include EGFR, IGFR, PDGFR and VEGFR [169]. EGFR: Its amplification is considered to play a key role in GBM development. In gliogenesis, JAKSTAT pathway interacts with EGFR. Dysregulated EGFR also activates STAT3 signaling. Both are considered to be important players in the glioblastoma development $[16,17]$. The negative regulatory mechanisms of EGFR become dysregulated in GBM [34].

BMPs act as gliogenic regulator in the process of gliogenesis. They act as negative regulator of EGFR. It is important to remember that BMPs cause the cell cycle to exit [29,30].Notch signaling is involved in astrocytogenesis. The EGFR is also interlinked with NOTCH signaling. Notch signaling is regulator of EGFR and this EGFR amplification is also modulated by dysregulations in TP53. The notch signaling and EGFR, both are upregulated in GBM. EGFR interacts with RAS-RAF-MEK-ERK and the PI3K-AKT-mTOR cascades.It also interacts with CDKs.

SOX9 is involved in gliogenesis and its dysregulation contributes to stemness in GBM. SOX9 interacts with EGFR in GBM oncogenesis [41].EGFR-AKT-Smad signaling is also another way via which SMAD contributes to GBM [47].

EGFR is considered to play key role in GBM development. Its cross-talk with SHH in GBM, further fuels oncogenesis. The EGFR signaling down-regulates the gene expression of negative regulators of Shh signaling pathway. This further fuelsthe cascade of downstream pathological changes such as by impacting the gene expression of Akt, ERK and others [42, 43].

NF-KB has been found to play very important role in GBM oncogenesis as it also plays role in EGFR amplification. EGFR amplifications also contribute to Pyruvate kinase M2 (PKM2) dysregulations, resulting in the upregulation of this rate limiting enzyme of glycolysis in GBM. In GBM, NF-KB and EGFR interactions contribute to GBM oncogenesis. In GBM, EGFR amplifications impact the MAPK, PI3k/AKT pathway, JAK/STAT pathway and contribute to the progression of GBM development.

Netrins play very important role in gliogenesis and their role is also crucial in GBM oncogenesis. Netrins also interact with the EGFR. This reduces partially the GBM cell senescence that occurs from DNA damage. This EGFR based role is mediated by AKT and ERK signaling pathway $[63,64]$.

In neurogenesis, EGFR interacts with the numb gene to modulate the process of neuronal differentiation. Numb gene negates Notch signaling and contributes to neuronal differentiation [132]. Upregulation of Numb genes contributes to halting GBM growth and progression [65] [78, 79, 80, 81].

Another very important role of EGFR in neurogenesis includes its involvement with Notch/STAT3Ser/Hes3 Axis. Hes3 has role of pro-survival signaling. It has strong relationship with $\mathrm{SHH}$, and 
potentiates the FGF and EGFR signaling. It is one of the key regulators with the ability to reprogram cells into NSCs. In GBM, this signaling axis becomes severely dysregulated [66].

PDGFR: It plays diverse role in the gliogenesis and neurogenesis. It plays very important role in neurogenesis but in the process of GBM development it contributes to oncogenesis. Such as PDGF and NT3, they both are neurogenic in neuronal development, but in GBM landscape they play oncogenic role $[63,64]$.

It is important to mention here that IGF-1, FGF, PDGF, EGF, Insulin are based on receptor tyrosine kinase and they all have significant roles in GBM development. Like EGFR, dysregulated PDGFR also activate STAT3 signaling[76].

The SMAD proteins which are involved in gliogenesis, they are of key significance. Dysregulations in SMAD alters the role of PDGF-B in GBM. When Smad, PI3K and FoxG1 signaling pathways are dysregulated, they switch the TGF-beta to become oncogenic.

In GBM development, when SHH becomes deregulated it also contributes to dysregulated PDGFR signaling. NF-KB is linked with TNF alpha and IL1 expression. It has major interaction with PDGFR in GBM oncogenesis. In gliogenesis, PDGFR works with MAPK pathway. When PDGFRbecomes dysregulated in GBM, it also impacts the MAPK signaling [77].

IGF-1: It works with FGFR3 in gliogenesis but it becomes one of the key oncogenic drivers in GBM development. FGF also works with IGF-1 to regulate the MAPK pathway. The role of IGF-1 in cancer development is well established. IGFR signaling pathway interacts with AKT to further the GBM proliferation [91] [13, 14, 15].

VEGFR: When Notch signaling that plays key role in gliogenesis becomes dysregulated, this results in upregulation of Akt and VEGF signaling and contribute to GBM development. There is also simultaneous decrease in PTEN expression [48].PAX6 and TGF beta also control the VEGF expression in GBM and prevents angiogenesis. They both stop the cells from entering S-phase of cell cycle and also induce apoptosis. The NF-KB promotes IL6, IL8, VEGF, and this further fuels the GBM development[76, 71].

\section{- RAS pathway in GBM and gliogenesis/neurogenesis:}

It becomes affected by alterations in FGFR3 which is one of the key gliogenic pathways. The alterations in Notch and SHH also impact the EGFR which in turn also impacts the RAS signaling. The loss of tumor suppressor in NF1 also causes RAS over-activation. Dysregulations in RAS also contribute to MAPK signaling alterations and contribute to GBM oncogenesis [10] [66] [76]. MEK signaling is involved in gliogenesis. The RAS over-expression also dysregulates the MEK signaling in GBM.

HOPX contributes to the regulation of NOTCH signaling and also causes senescence by activating the Ras and MAPK pathway[63, 64].

Ephrins which are involved in gliogenesis. In GBM, the dysregulation of ephrins contribute to the RAS over-activation [105] [108]. In neuronal differentiation, RAS interacts with key neuronal differentiation factor NeuroD. GSK3 beta has important contributions towards GBM oncogenesis. It also contributes to the GBM progression by contributing to RAS over-expression [160, 161]. 


\section{- PI3K/AKT/mTOR:}

JAK-STAT pathway, MAPK, EGFR and NOTCH have major interactions with PI3K/AKT/mTOR Pathway in process of gliogenesis $[16,17]$. SMAD dysregulations also impact PI3K/AKT/mTOR and cause the TGF beta to become oncogenic[46].EGFR-AKT-Smad signaling is also another way through which SMAD contributes to the GBM. The TGF- $\beta 1$ works with Smad, p38 MAPK and PI3K/Akt signaling pathways in GBM development [47].Neuregulin-1 is a gene of EGF family and contributes to the astrocytogenesis. Nrg1 and erb receptor signaling pathway interact with each other and also with PI3K pathway, thus contributing to the growth of GBM [78, 79, 80, 81].

NRSF/REST halts the neurogenesis and induces gliogenesis. It works with PI3k in GBM oncogenesis [83]. The GSK3 also works with PI3K/FGF signaling pathway and contributes to the stability of cMyc. In GBM, all of them become dysregulated. GSK3 has interactions with many genes and pathways that are involved in GBM such as PI3k/AKT/mTOR pathway $[160,161]$. PI3k/AKT/mTOR pathway contributes to the gliogenesis and neurogenesis but also contributes to stemness in GBM [162].

- PTEN: The role of PTEN is very significant as it also contributes towards controlling the SHH and PI3K expression. When PTEN becomes defective in GBM, then SHH and PI3K becomes dysregulated and both contribute to the oncogenesis [36] [62].PTENacts as tumor suppressor and it also impacts $\mathrm{SHH}$ and PI3K pathways.

NF-KB also interacts with the PI3K/AKT pathway. With loss of PTEN and NF1, the PI3K/AKT pathway also becomes dysregulated [41] [76].PTEN regulates PI3k and blocks AKT signaling [77].

Notch dysregulation causes simultaneous decrease in PTEN expression, resulting in the upregulation of Akt and VEGF.

Sox9 which is also involved in maintaining pluripotency of NSCs, it also interacts with PTEN. The PTEN works as a tumor suppressor by controlling the gene expression of STAT3 [42, 43].

PAX6 stops the cells from entering S-phase of cell cycle and also induces apoptosis. It also interacts with PTEN to regulate the cell cycle [71]. Loss of PTEN causes the PI3k/Akt pathway to become dysregulated. CNS neural progenitor marker Pax 7 also becomes upregulated in glioblastomawith PTEN deficiency [115]. GSK3 beta also interacts with tumor suppressors including PTEN [160, 161].

\section{- NF1:}

NF1 contributes to the regulation of NSCs proliferation and gliogenesis. Loss of NF1 leads to the drastic effects that lead to dysregulated NSCs proliferation and uncontrolled gliogenesis. This also impacts the downstream signaling and most significantly PI3K/Akt/mTOR pathway becomes dysregulated as a consequence. The NF1 negatively regulates the RAS-signaling pathway. With loss of NF1, the RAS/MAPK signaling pathways become dysregulated $[170,171]$.

Defects in NF1 impact both neuronal and glial cells. The impact of NF1 loss on neuronal cells is also of key significance as it contributed to abnormalities in cAMP generation in such cells. The GFAP works also by interacting with NF1 and it has capacity to impact the NF1 gene expression in order to enhance glial proliferation. The NF1 expression is essential in neuronal differentiation as well. Other key pathways that interact with NF1 include Notch, ERK, MEK, SMAD3 and Hes1 [172]. 
ERK pathway works in a delicate regulated balance with NF1. The ERK pathway works as a G1 to S transition switch when upregulated. It has key interactions with many key regulator genes/signaling pathways such as SHH, FGFR3, JAK-STAT, Notch, EGFR, ephrins, netrins, NeuroD, GSK3, CDKs [173] [174].Nf1 inactivation leads to the increased gliogenesis and this declines the neurogenesis. The MEK/ERK pathway becomes upregulated and hyperactive. Thisdysregulates NSCs proliferation and increases the risk of GBM [175].Nf1 mutations are of prime significance in mesenchymal subtype of GBM [176].

\section{- FOXO axis:}

This axis promotes differentiation and negatively regulates proliferation. This axis is dysregulated in GBM. The PI3k/AKT pathway negatively regulates FOXO axis. This axis interacts with IGF1 as well. The role of FOXO is also governed by the pathways with which it interacts. In GBM oncogenesis, the dysregulated Akt cause the FOXO axis to become dysfunctional [177].FOXO axis plays very significant roles as it works with TGF beta/SMAD axis. This plays a vital role in the process of gliogenesis and neurogenesis. The IGF1 suppresses FOXO axis. IGF1 signaling also promotes cdkn1a expression [178].

PI3k/Akt, RAS, MAPK pathways inhibit the FOXO axis. They all have well established role in GBM development [179]. FOXO axis is damaged in GBM. The physiologic role of FOXO is also to regulate cell cycle. It also enhances the expression of sirtuin1 during cellular senescence. Several studies have indicated that FOXO1 has the ability to inhibit EMT and metastasis [180].FOXO is also being considered a target in treating GBM $[181,182]$.In GBM oncogenesis, Foxo/SMAD signaling is downregulated while FoxG1 works to enhance proliferation by increasing the expression of Sox2 and Sox5 [183].

2. P53 signal alteration:

- P53:

P53 plays diverse functions ranging from neurogenesis to NSCs and brain development. P53 is dysregulated in GBM oncogenesis. The consequences of p53 loss on neuronal differentiation are still controversial as it is yet to be fully understood how it impacts NSCs. Although it is likely that p53 inhibits neuronal differentiation of NSCs [184][185].

Studies involving brain organoids have shown p53 to be a crucial player in CNS development. It also contributes to genomic stability and regulates neurogenesis [186].Dysregulations in P53 also contribute to Mdm amplifications in GBM. In GBM, damage to P53 also dysregulates the notch signaling, GSK3 beta, Ras/MAPK, PI3k/mTOR pathway, EGFR signaling and others.

It is important to note that deletions of P53 and REST are so significant that it causes the cells to switch into pro-neural type of GBM. Loss of p53 in Li-Fraumeni syndrome also results in GBM development. This also makes p53 a major player in GBM oncogenesis $[187,188]$.

Cyclin-dependent kinase inhibitor 2A (CDKN2A): It is a tumor suppressor and works with Rb1 to halt G1 to $S$ phase transition. It encodes two tumor suppressor proteins P16 and ARF. CDKN2A mutations are associated with Glioblastoma development. ARF functions as stabilizer of P53 and sequesters the MDM2 
which is a degrader of p53.CDKN2A mutation is also linked with EGFR amplification that is a major part of GBM oncogenesis [189]. MDM2 and MDM4 both have structural similarities and are p53 binding proteins. MDM4 is capable of reversing MDM2-based degradation of $p 53$, but the apoptotic functions of p53 remain suppressed. MDM2 becomes over-expressed in GBM resulting in increased degradation of p53 [190]. Aging is also considered to play important role in the dysregulation of EGFR, Mdm2,andp53 [191].

3. RB signal alteration:

\section{- RB1:}

$\mathrm{Rb} 1$ is a tumor suppressor. It is also involved in neuronal differentiation. Rb1 interacts with CDKs in regulating cell cycle. This pathway becomes damaged in GBM and CDKs cause E2F based G1 to $S$ transition [192]. It also contributes to differentiate the NSCs into astrocytes. Mutated Rb1 is considered a major player in GBM oncogenesis. P16-CDK4-RB pathway works in an interconnected manner and control cell cycle progression [193]. Rb1 knockout mouse models have been shown to increase the neurogenesis as a result. Rb1 interacts with CDKs in inhibiting E2F. This pathway becomes damaged in GBM and CDKs cause E2F based G1 to $S$ transition [194].

Cyclin-dependent kinases and inhibitors: CDKN2B forms complex with CDK4 and CDK6.This halts the activation of CDKs. CDKN2B regulates the progression of $\mathrm{G} 1$ phase of cell cycle. CDKN2C also forms same complex but it works more with Rb1 expression. TGF-beta induces CDKN2B. It regulates the cell cycle and is also key player in gliogenesis. TGF beta works with SMAD and CDKN2B to regulate cell cycle and gliogenesis. They also inhibit c-myc. CDKN2B also plays role in neurogenesis while working with PAX6. It is important to mention here that Sox 2 and sox4 are involved in the stemness of GBM cells, they cause the downregulation of CDKN2B $[196,197]$.

CCND2 forms complex with CDK4 and CDK6. This contributes to $\mathrm{G} 1$ to $\mathrm{S}$ cell transitions and inactivates the Rb1 for this purpose [195].

SOME OTHER MUTATIONS IN GBM: briefly explored here as deeper investigation into all of them is beyond the scope of this study.

IDH1: Mutant IDH1 contributes to the GBM development and ultimately contributes to oncogenesis through epigenetic mechanisms as well [198]. IDH1 mutation alters the neurogenic niche and promotes glioma formation. Resultant accumulation of 2-hydroxyglutarate alters DNA methylation and histone binding. This contributes to the oncogenic changes in neuronal and glial cell types [199]. Similarly, IDH2 has also emerged to play similar role in GBM oncogenesis.

IDH mutations are considered to be among the initial mutations in GBM development. They are also common in diffuse gliomas. IDH mutations are more common in secondary GBM and far less common in primary GBM [200]. 1p/19q loss has been found to occur with IDH1 mutations in oligodendrogliomas [201]. 
TERT: It is upregulated in stem cells including cancer stem cells. It is also related to the pluripotency of cells. It interacts with STAT3 which also has major involvement in the process of gliogenesis. The dysregulated STAT3 signaling is involved in glioblastoma development. Another major interaction of TERT is with GSK3 beta. The GSK3-beta deletions contribute to the enhanced proliferations of neural progenitor cells with simultaneous increase in SOX2 and beta-catenin. In normal cells, it acts as negative regulator of Epithelial-Mesenchymal-Transitions (EMTs) and many proto-oncogenes. But dysregulated GSK3-beta is oncogenic.TERT plays a wide array of roles ranging from cellular aging to epigenetic clock $[202,203]$

Similarly, ATRX is important component of chromatin remodeling complex. Its dysfunction also causes immense genomic instability. This alteration is present in 44\% of GBM [204].

FUBP1: In undifferentiated NSCs, FUBP1 induces the expression of c-myc. The c-myc interacts with JAKSTAT and is downregulated by SMAD/TGF beta pathway in gliogenesis. The c- myc is also involved in neurogenesis but plays the oncogenic role in GBM development. Cancer stem cells are heavily associated with the Wnt signaling. The dysregulated Wnt signaling causes the activation of cyclinD1 and c-myc, causing G1 to S phase transition. It also contributes to Epithelial to Mesenchymal transitions $[205,206]$.

\section{GLIOBLASTOMA SUBTYPES AND VAST HETEROGENIETY:}

The Cancer Genome Atlas identified 840 genes involved in GBM, leading to the ultimate classification of glioblastoma into three subtypes [207, 208, 209].

\section{Pro-neural subtype:}

This subtype is present mostly in younger patients. They tend to survive longer. It has the highest subtype shifting and most favorable survival [210].IDH1 is one of the key genes involved in this subtype. It is also considered the reason for favorable prognosis. IDH1 mutant form is present with 1p/19q co-deletion [211]. Other important mutations include p53 dysfunction, PDGFR amplifications, upregulated Nkx 2-2 and Olig2. Most low grade glioblastomas and secondary glioblastomas belong to pro-neural subtype.Some most common GBM abnormalities such as chromosome 7 amplification and chromosome 10 deletions have low occurrence in this GBM subtype [212]. The EGFR, PTEN and Notch are normal in this subtype [213].

\section{Classical subtype:}

It is the most common subtype and key genetic alterations include EGFR amplifications, homozygous deletion of CDKN2A, chromosome 7 amplification and others [214].Abnormalities in IDH1, TP53, PDGFR and NF1 are mostly absent in this subtype [215].

\section{Mesenchymal subtype:}

It is the most stable subtype. Signature mutations include NF1, NF-KB and upregulated gene expression of S100A1, CHI3L1, MET, VEGFR2, CD31, fibronectin, COX2. There is increased inflammation and necrosis in this subtype [216].

There are fewer alterations of EGFR in this subtype. Pro-neural markers are dysregulated in this subtype. The alterations in TGF-beta and STAT3 play key roles in the transition from pro-neural to 
mesenchymal subtype. The proneural-mesenchymal transition upon tumor recurrence has been suggested as a mechanism of tumor resistance to multimodal therapy $[217,218]$.

The relationship between neurogenesis/gliogenesis and the key genes/signaling pathways involved in the subtypes has beeninvestigated in the earlier sections.

\section{SIGNIFICANCE OF HETEROGENIETY IN GLIOBLASTOMA:}

Glioblastomas are one of the most aggressive tumors with multiple subtypes and are widely known to have vast heterogeneity in nature. This heterogeneity is also evident among the pro-neural, classical and mesenchymal subtypes of GBM. The genetic landscape of GBM is so diverse that there is lots of intratumoral heterogeneity as well. The landscape of GBM has vast heterogeneity that key epigenetic alterations such as those emerging because of IDH1/2 mutations, they are different in 3 subtypes and among different samples of GBM. Multiple studies have pointed out that landscape of GBM mutations vary to such an extent that RTK/RAS/PI3Kalterations have been detected in $83 \%$ of samples, the TP53 alterations in $87 \%$, the RB1 alterations in $78 \%$ of the samples. Still there is lots of variability in even in core mutations among different samples $[219,220,221]$

There may be multiple factors that are responsible for this vast heterogeneity in GBM. Based on the results of this study, it is hypothesized here that this genetic variability may have origin in the differences between the genetic landscape of gliogenesis and neurogenesis. NSCs are the progenitors of both neurons and glial cells. The initial mutations that occur in three subtypes of GBM may drive the direction of subsequent mutations in tumor development. The internal genetic and epigenetic homeostasis that is established at the time of establishment of cell fate, when this homeostasis is dysregulated then the risk of glioblastoma oncogenesis increases. Aging plays a very significant role in GBM development as majority of the GBM cases are in old age. But the pro-neural subtype of GBM affects mostly younger patients and here different set of mutational landscape impacts GBM development. The timing and sequence of initial driver mutations also play very important role in altering the internal cell circuitry and direction of further mutational changes involved in GBM progression.

In depth further discussion of GBM core pathways, heterogeneity and subtypes is beyond the scope of this study.

\section{Discussion:}

\section{Cell type specification as the factor determining the risk of future oncogenesis:}

Neurons and glial cells both originate from neural stem cells (NSCs), despite this both are predisposed to different diseases. The number of tumors that originate in glial cells is so much higher comparatively. GBM is a grade- 4 astrocytoma, while there are very few tumors that originate from neuronal cells such as medulloblastoma. The medulloblastoma mostly occurs in the young adults.

Aging plays a very crucial role in affecting glial cells and as well as neurons. The risk of

neurodegenerative diseases including Alzheimer's disease increases several fold in elderly, resulting in the massive degeneration of neurons. The risk of Glioblastoma also increases several fold in elderly.Glial cells including astrocytes are considered to be major contributors to the GBM oncogenesis. By 
investigating genes and signaling pathways that are gliogenic and neurogenic, this study finds that the glial cells including astrocytes possess increased proliferative potential in comparison to neurons, it predisposes them towards the increased risk of oncogenesis.

The cell circuitry in glial cells including astrocytes works in an integrated and deeply interconnected manner. For example, the EGFR is considered to be one of the key factors in GBM oncogenesis. In glial cells, the EGFR is upregulated along with ERK/AKT pathways in response to aging. There are many sets of upstream/downstream genes and signaling pathways which can be dysregulated by alterations in other related genes. Many such key genes are interconnected with JAK-STAT pathways which also exert control over other regulators of proliferation such as PI3K/AKT/mTOR pathway. Further cascade of pathological changes may lead to dysregulation of SOX2. This may contribute to enhancethe stemness and invasiveness of GBM cells. This accumulation of dysregulations unfolds a cascade of changes that unleashes havoc in cell circuitry, ultimately leading to switching the cells towards oncogenesis. There are many gliogenic genes (JAK-STAT, hes and others) and pluripotency related genes such as FGF3, notch, wnt and others, which in developmental mechanisms are very delicately regulated but they also possess the potential to contribute to the GBM oncogenesis upon being dysregulated.

While despite being the descendent of the same neural stem cells (NSCs), neurons and glial cells are very different cell types. Neurons are permanent cells with very limited and controlled expression of proliferation related genes. It is because of the specific neurogenic genes that exert immense control over proliferative genes and signaling pathways to the extent that when their gene expression is induced, it also halts the proliferation in GBM cells. To a great extent, they also likely preventneurons from the future risk of oncogenesis but predispose them more towards neurodegeneration in later life. The inverse relationship between Alzheimer's disease and cancer biology has already previously been investigated by the author [163].

\section{Predisposition of glial cells towards the glioblastoma development:}

Similarly like NF-KB signaling, the NRSF/REST gene expression is also upregulated with aging. This results in predisposing the cells towards more proliferative signaling. This genetic switching of the cells by the genes including NRSF/REST and others tend to predispose cells towards the increased risk of oncogenesis. The NRSF/REST expression has limitations in neuronal cells because they can interfere with neuron specific genes, but such limitations are not present in glial cells such as astrocytes. Hence, they become predisposed to increased risk of oncogenesis due to the nature of cell circuitry they possess. PAX6 expression in the maintenance of neuronal cells and its apoptotic effect in GBM tumor cells,are also very important in signifying the impact of cell type specific genetic programming in disease predisposition. This also signifies how cell type specific genes based on the nature of cell circuitry and cell type such as permanent or stable or labile; determine the risk of future disease predispositions. For example, the risk of GBM in glial cells or the risk of Alzheimer's disease based neurodegeneration in neurons.

\section{Key neurogenic genes with ability to control oncogenesis in glioblastoma cells:}

PAX6, Neurogenins including Ngn1, NeuroD1, NeuroD4, NKX6-1 Ebf, Myt1, ASCL1 
The role of Numb is controversial as it promotes neuronal differentiation and halts GBM oncogenesis, but its gene expression has also been detected in GBM mesenchymal cells.

\section{Key gliogenic genes with ability to control oncogenesis in glioblastoma cells:} p300, BMP, PAX6 (anti-GBM override), HOPX (tumor suppressive + differentiation), NRSF/REST (astrcytogenic but capable of playing oncogenic role), LIF, TGF beta.

BMP is also involved in the neuronal development but it primarily has far greater gliogenic role.It is involved also in induction of neurogenin and ASCL1. Both are key regulators and have negative regulatory effects on GBM progression. The FGF signaling pathway also plays one of the key important and complex roles in gliogenesis. . In GBM, FGF signaling pathway has been found to work with MAPK in GBM oncogenesis.But FGFR1 and FGFR2 also promote differentiation in glial cells.

There are around 350 gliogenic genes and 100 transcription factors that are involved in astrocytogenesis, but the GBM landscape is vast as it includes also the stemness related genes.

\section{Gliogenic vs. neurogenic programming of cells: determines the riskof disease predisposition in later life} Neurons are permanent cells while glial cells possess high proliferative capabilities. Such cell fate specifications based on cell types and their proliferative potentials act to determine the future disease predispositions. Neurons due to limited proliferative potentials are predisposed to the increased risk of neurodegeneration with aging, while astrocytes are at more risk of tumor development such as astrocytomas.

The key neurogenic genes including PAX6, neurogenins including Ngn1, NeuroD1, NeuroD4, NKX6-1 Ebf, Myt1, ASCL1, Numb and others govern the neurogenic cell fate of neurons. They also decide the cascade of downstream genes which make neurons permanent cells by regulating cell cycle.

There is already age related increase in gliogenesis, further increasing the risk of developing GBM. With aging, more and more NSCs begin to switch towards becoming astrocytes mediated via. STAT3. There is age related decline in NSCs pool. The result is more astrocytogenesis and less neurogenesis [164]. In gliogenic programming around 350 genes and 100 TFs play role. Unlike neurons, glial cells are not permanent cell type. They have comparatively high capacity to proliferate and in cases of neurodegeneration or stroke, gliosis is of common occurrence.

Cell type specific programming of glial cells determines the gene expression of glial cells and the euchromatin areas are predisposed to damage that may result in amplifications or deletions of genes. Overtime this damage accumulates to the extent that cell cycle converges towards oncogenic $\mathrm{G} 1$ to $S$ cell transitions in GBM, ultimately leading to stemness in GBM.

The cell type specifications are not based on one gene but on combinations of genes and signaling pathways, hence called combinatorial code. Targeting any one gene such as EGFR, fails to control the GBM oncogenesis and progression. This is because the dysregulations in one pathway or gene causes a cascade of downstream effects; hence the rest of oncogenic circuitry remains intact.

GBM is considered a grade-4 astrocytoma. The genetic dysregulations of immense magnitude such as those contributed by REST, wnt, shh, they are able to override the gene expression of otherkey genes whose purpose is to keep the cell in specific differentiated state and to prevent uncontrolled proliferation. 
These dysregulations accumulate to contribute towards the progression of GBM. It results in the decline of cell type specific differentiated state and contributes to de-differentiation, increasing the grade and aggressiveness of tumor.

\section{GBM Oncogenesis: a consequence of deviation from gliogenic differentiated fate}

Based on the findings of this study, this study postulate a possible sequence of key changes that unfolds and ultimately leads to GBM development. The risk of GBM increases several folds with aging. The origin of GBM is not based on the aberration of any one gene or signaling pathways. It originates as a consequence of and as accumulative effect of a wide variety of changes that dysregulate the cell circuitry of glial cells such as astrocytes. One example of such dysregulations include FGF pathway which also acts as neurogenic to gliogenic switch but when dysregulated it contributes to GBM development and becomes oncogenic.

In GBM oncogenesis, the initial sequence of oncogenic changes may vary as GBM occurs in sporadic manner and as well as part of other syndromes including in NF1, with loss of P53 in Li-Fraumeni syndrome and others $[165,166,167,168]$.

When dysregulations in cell circuitry exert enough control over the genes that keep cells differentiated in specific cell types (key gliogenic genes here),this leads to disruptions in the cell type specific programming or combinatorial code that governs and maintains cell types in their respective differentiated states and maintains homeostasis.

\section{Possible landscape of GBM development:}

Here we focus on the possible ways through which one oncogenic mentation in GBM leads to another and how interconnectedness of GBM circuitry may contribute to GBM progression. The GBM landscape varies depending on subtypes and intra-tumor heterogeneity. Here we are postulating the GBM development landscape on the basis that how the emergence of oncogenic changes is capable of inducing further oncogenesis.

1. With aging, there is increase in levels of inflammation. The NF-KB gene expression becomes upregulated. This leads to the upregulation and amplification of EGFR.

2. EGFR amplifications contribute to the JAK-STAT dysregulations.

3. JAK-STAT dysregulations trigger a cascade of changes that further deviates the cells away from their differentiated state. This also leads to STAT3 dysregulations.

4. JAK-STAT pathway downstream targets include Bcl-xL, Bcl211, Bcl-2, cyclin D1, and c-Myc.The leads to the dysregulated STAT3 signaling.

5. BMPs which have major gliogenic role and also negatively regulate GBM. The EGFR amplifications also overcome the negative regulatory effect of BMPs.

6. The NF-KB also disrupts the notch signaling and alters the gene expression of cyclinD1.

7. Dysregulated Notch also causes simultaneous decrease in PTEN expression. This resultsin upregulation of Akt and VEGFR gene expression. 
8. As PTEN controls SHH and PI3K, the PTEN dysfunction also makes both SHH and PI3K dysregulated. This causes the the dysregulation in PI3k/AKT/mTOR pathway.

9. SHH also has major interactions with key signaling pathways including TGF-beta, wnt/beta-catenin, notch and also interacts with K-RAS, PKA and others.

10. EGF motifs and Notch signaling are interlinked. The EGFR amplifications also disruptthe notch signaling. Notch signaling is also the regulator of EGFR and this amplification is also modulated by dysregulations in TP53.

11. Notch also interacts with Hey1, PI3K/AKT/mTOR and ERK/MAPK pathway. This contributes to the proliferative and survival signaling in GBM development.

12. NOTCH works with FGF to keep NSCs in proliferative stage. Both are dysregulated in GBM.

13. EGFR interacts with RAS-RAF-MEK-ERK and the PI3K-AKT-mTOR cascades and also interacts with CDKs.

14. EGFR amplifications also contribute to Pyruvate kinase M2 (PKM2) dysregulations, resulting in the upregulation of this rate limiting enzyme of glycolysis in GBM.

15. Dysregulations in EGFR and PTEN, also lead to the upregulation of Sox9 which contributes to further oncogenesis.

16. Dysregulated EGFR, FGF, PDGF, c-MET, also activate STAT 3 signaling. Dysregulated STAT3 contributes to upregulation of Leukemia inhibitory factor receptor beta (LIF) which plays oncogenic role.

17. JAK-STAT pathway also has major interactions with TGF-beta which in normal glial cells prevent the cells from $\mathrm{G} 1$ to $S$ transition. Dysregulations in JAK-STAT also impact TGF-beta.

18. Physiologically, TGF-beta regulates SOX2 and SOX4. Dysregulated TGF-beta may have far reaching consequences as SOX2 and SOX4 have been found to play role in GBM stemness.

19. SOX2 induces ASCL1 and TLX TF, and their dysregulation inhibits TGF Beta.

20. Sox2 is also interlinked with JAK-STAT signaling pathway, and both become dysregulated in GBM.

21. $\mathrm{P} 300$ is a very strong regulator of gliogenesis. It is also repressor of nestin which is also involved with stemness and interacts withSox2. The c-myc gene overrides p300 and then GFAP. The leads to the upregulation of nestin.

22. TGF-beta regulates the cell cycle and cause the cytostasis by downregulating gene expression of cMyc. This prevents $\mathrm{G} 1$ to $\mathrm{S}$ transitions. TGF-beta together with SMADs plays important gliogenic role in normal development, but their dysregulated versions are oncogenic.

23. Dysregulated TGF beta also dysregulates PDGFR signaling.

24. Loss of tumor suppressors including p53, PTEN, this loss also contributes to the GSK3 dysregulations.

25. GSK3 has interactions with many genes and pathways that are involved in GBM oncogenesis such as PI3k/AKT/mTOR pathway, wnt, notch, shh, ras, raf, mek, erk, APC, axin, sox2, beta catenin and others. 
26. In normal cells, the GSK3-beta acts as negative regulator of EMT and many proto-oncogenes but dysregulated GSK3-beta is oncogenic.

27. REST gene: The direction of cell circuitry guided by it tends to have high proliferative potential. With aging, the gene expression of REST increases, further predisposing glial cells to oncogenesis.

28. REST also interacts with SHH, Wnt and PI3K signaling pathways. All of them have well-established role in GBM oncogenesis.

29. REST has strong interactions with the wnt signaling pathways. It also downregulates the genes involved in apoptosis.

30. The dysregulated Wnt signaling causes the activation of cyclinD1 and c-myc, causing G1 to S phase transitions. Dysregulated WNT also contributes to Epithelial Mesenchymal Transitions (EMT).

It is important to note that the landscape of all genes involved in GBM development is very vast. These above mentioned points focus on the key genes/signaling pathways based on the findings of this study to postulate the possible sequence of events through which GBM unfolds and develops. As the GBM landscape is vast, the sequence of mutations involved in GBM oncogenesis may vary but they always converge to cause the pathologic $\mathrm{G} 1$ to $\mathrm{S}$ transitions, ultimately leading to GBM development and progression.

\section{The targets for gene editing and epigenome editingin the development of future GBM therapies:}

The findings of this study also provide the targets for gene editing tools such as CRISPR gene editing or epigenome editing to correct or regulate the genes/signaling pathways which become dysregulated in GBM development. This study may serve as a map for genetic and epigenetic targets for the development of new therapeutic approaches as it investigates the gliogenic and neurogenic genes/signaling pathways:

1. Having the ability to control oncogenesis in glioblastoma cells

2. Having gliogenic/neurogenic roles but in the GBM development contribute to the process of oncogenesis.

3. Having the ability to contribute to the gliogenesis or neurogenesis but also contribute to the stemness in GBM.

New potential therapeutic approaches may be devised with the goal to revert, halt or to control glioblastoma onset, development and progression by targeting related gliogenic or neurogenic genes/signaling pathways as identified in this study.

\section{Conclusion:}

Glioblastoma originates when the gene expression of key gliogenic genes and signaling pathways becomes dysregulated. This study identifies key gliogenic genes/signaling pathways having the ability to control oncogenesis in glioblastoma cells includingp300, BMP, PAX6(anti-GBM override), HOPX (tumor suppressive + differentiation), NRSF/REST (astrcytogenic but capable of playing oncogenic role), LIF, TGF beta. 
It also identifies related key neurogenic genes/signaling pathways having the ability to control oncogenesis in glioblastoma cells including PAX6, neurogenins including Ngn1, NeuroD1, NeuroD4, Numb, NKX6-1 Ebf, Myt1, and ASCL1.

This study also postulates how aging contributes to the onset and origin of glioblastoma by increasing the gene expression of NF-KB, REST/NRSF, ERK, AKT, EGFR and others. This is further detailed in the 'discussion' section. It also evaluates how dysregulation of the key genes sets in motion a cascade of downstream changes that lead tothe GBM oncogenesis. The origin of GBM is dependent on the multiple genes and pathways that accumulatively converge towards the disease development.There are multiple layers of steps in glioblastoma oncogenesis including the failure of cell fate specific genes (such as p300, BMP, HOPX, NRSF/REST and others) to keep the cells differentiated in their specific cell type. The dysregulations in genes and signaling pathways (such as wnt, notch, shh) that are common to multiple cancers, also play significant role in GBM.The genetic regulators that are involved in pluripotency also become upregulated (such as sox2, oct4, c-myc), finally contributing to the development of cancer stem cells. They also have interactions with normal cell circuitry such as the interaction of Sox 2 with JAK-STAT pathway. There is interconnected delicate balance of expression inthe cell type specific and survival related genes. Such delicate balance is required for the maintenance of cell type and cell survival. When it becomes dysregulated beyond a specific threshold, it contributes to the development of glioblastoma. In GBM development, when the genetic dysregulations in key genes/signaling pathways that govern the cell fate and survival accumulate beyond a specific threshold, such dysregulations lead to the switching of cells towards the glioblastoma oncogenesis. Suchmutations are capable of overriding the physiologic direction of cell cycle/circuitryby altering the gene expression of other gliogenic genes, proto-oncogenes and tumor suppressors.

\section{Abbreviations:}

GBM: Glioblastoma Multiforme NSCs: Neural Stem Cells IL: Interleukin CNTF:Ciliary neurotrophic factor LIF.Leukemia inhibitor factor CT-1: Cardiotriphin-1 FGF: Fibroblast Growth FactorJAK: Janus Kinase STAT: Signal Transducer and Activator of TranscriptionSOX: SRY (sex determining region Y)-box BMP: Bone Morphogenetic ProteinsNIFA: Notch effector proteinEGFR: Epidermal growth factor receptor GFAP: Glial fibrillary acidic proteinTGF beta: transforming growth factor betaCBP: CREB-binding protein Hey1: Hairy/enhancer-of-split related with YRPW motif protein 1 HES1: hairy and enhancer of split-1 DTX1: Protein deltex-1SHH: Sonic hedgehog PTEN: Phosphatase and tensin homologPAX: Paired box protein

Mek1: mitogen activated protein kinasePKC: protein kinase CPI3K: Phosphoinositide-3 kinaseNPCs: Neural progenitor cells

CDKs: Cyclin dependent kinasesPKM2: Pyruvate kinase M2P53:Tumor protein P53VEGF: Vascular endothelial growth factor

TF: Transcription FactorNANOG:Homeobox protein NANOGWnt: Signaling pathway Notch: Signaling pathway

GSK3: Glycogen synthase kinase 3PDGFR: platelet-derived growth factor receptorKLF6: Krueppel-like 
factor 6

NF-KB: nuclear factor kappa-light-chain-enhancer of activated B cellsEMT:Epithelial Mesenchymal Transition

Nrg1/Ngn1: Neuregulin-1NRSF/REST: Neuronal Restrictive Silencing Factor MAPK: mitogen-activated protein kinase

HOPX: Homeodomain-only proteinASCL2:Achaete-scute complex homolog 2NKX2-1: NK2 homeobox 1 mTOR: mechanistic target of rapamycinEFNB1: EphrinsNTN: NetrinsNeuroD:Neurogenic differentiation factor

DBX2:developing brain homeobox protein 2Nkx-6.1:Homeobox protein Nkx-6.1Myt1:Myelin transcription factor 1

Numb: Protein numb homolog Oct2: octamer transcription factor 2Myc: MYC proto-oncogene

\section{Study Design:}

The etiology and origins of Glioblastoma (GBM) are not entirely known. This study investigates the gliogenic and neurogenic genes/ signaling pathways to trace the origins of glioblastoma. This research study finds evidence from the already published research literature to find the changes that lead to the onset and development of glioblastoma. This also will help better understand the factors that predispose the glial cells more towards the risk of oncogenesis as compared to neuronal cells. The limitations are also explained in the 'Methodology', in the beginning of 'Results' section, and in other respective sections and headings.

Limitations of the Study: This study has cited studies based on the gliogenic and neurogenic genes/signaling pathway and has investigated them irrespective of GBM subtypes. Citation of studies was not based on any specific cell lines or specific tumor samples but was focused on evaluating the role of gliogenic and neurogenic genes in relation to their contributions in GBM oncogenesis.

Hence, another limitation of this study is that it does not differentiate among the findings emerging from in-vitro, in-vivo and in-silico studies. We address this by including only those studies in this research work whose results were also evident by other independent multiple studies, as there are sometimes problems regarding reproducibility of the results from in-vitro studies [222]. Due to vast heterogeneity in GBM landscape and even in same GBM sample, there is always possibility that one or more mechanisms present in one sample, they may be entirely absent in different tumor samples or subtypes [223]. In order to avoid overlooking unknown genes, this study takes a different approach and focuses on investigating the GBM development through the lens of gliogenic and neurogenic genes/signaling pathways. As the genetic landscape of gliogenesis and neurogenesis is very vast, hence it is not possible to focus on every gene in one study. There is always risk that other currently unidentified genes/signaling pathways may also be playing significant role in GBM oncogenesis. This study also tries to discuss the possible interconnectedness of genes/signaling pathways in GBM onset and progression in relation to the presence of specific mutations. The presence or absence of any mutation may alter the landscape of subsequent mutations. Mutational landscape also varies in different GBM subtypes and tumor samples. 
This study divides the investigated gliogenic and neurogenic genes/signaling pathways into three categories as they were focused to investigate their role in GBM development.

1. Those having the ability to control oncogenesis in GBM cells.

2. Those having gliogenic/neurogenic roles but in GBM development contribute to oncogenesis.

3. Key genes that contribute to gliogenesis or neurogenesis but also contribute to the stemness in GBM.

\section{Declarations:}

\section{Acknowledgements:}

I, Dr. Ovais Shafi, am truly grateful and thankful toDr. Ghazia Siddiqui because she is intelligent and imaginative, thoughtful andmarvelous.I'm always inspired by her in infinite ways. Her enthusiasm towards the field of medicine is astounding. She is capable of being a great physician scientist. I believe that her scientific curiosity, enthusiasm and intellectual skills all working together as one, are also one of the great sources of inspiration. She is not only passionate about the field of medicine but both medicine and research are also the expressions of the immense plasticity of her mind. She is also capable of conducting landmark research studies in any disease area.

Both authors Dr. Ovais Shafiand Dr. Ghazia Siddiquiare inspired by multiple researchers including: Dr. Robert Allan Weinberg - Daniel K. Ludwig Professor for Cancer Research at Massachusetts Institute of Technology (MIT), director of the Ludwig Center of the MIT, and American Cancer Society Research Professor.

Dr. Brian J. Druker - physician-scientist at Oregon Health \& Science University, in Portland, Oregon. He is the director of OHSU's Knight Cancer Institute.

I, Dr. Ovais Shafi, am also thankful to my remarkable father 'Dr. Shafi Uddin', my remarkable mother 'Firdous Shafi', and then all my family members for their moral support and motivation. It is the continuous supporting and understanding nature of my parents that also is always truly helpful for me. I am also thankful to my friend 'Philip Joseph Parker' for his kindness and motivation. He is a brilliant person with great enthusiasm and interest in medical research.

I am thankful to the Nobel Prize Winning Scientist 'Marie Curie', Physicist Scientist 'Prof. Stephen Hawking', and Physician Scientist 'Dr. Brian Druker' of American Association for Cancer Research (AACR) on being great inspiration for young researchers including me.

I'm thankful to Dr. Viqas Shafi for his support. He is Pharm.D from Dow College of Pharmacy - Dow University of Health Sciences, Karachi, Pakistan. He has vast expertise in the domains of pharmacology and is interested in research areas including pharmacotherapy in relation to disease pathophysiology, pharmacogenetics, toxicology in geriatrics, clinical trials, receptor polymorphisms and others. He also possesses vast expertise in non-clinical pharmacology.

\section{Funding:}

I declare that there was not any source of funding for this research work. This research study finds evidence from already published research literature to investigate the origins and development of glioblastoma. 
Availability of data and materials:

The datasets supporting this article are included within the article, in the 'References' section.

\section{Competing interests:}

The authors declare that they have no competing interests.

\section{Consent for publication:}

"Not applicable".

\section{Ethics approval and consent to participate:}

"Not applicable".

\section{Authors' contribution}

Authors: Ovais Shafi (OS), Ghazia Siddiqui (GS).

1. Ovais Shafi (OS) is the author of the manuscript and was involved in the idea, concept, design, and methodology of the study, literature search and references. He did the writing, editing, and revision of the manuscript. He was involved in drawing the findings, interpretation of the data and was involved in all aspects of the study.

He prepared and wrote discussion, results and conclusions of the study. OS extracted and analyzed the data. He was involved in critical evaluation and audit of every aspect of the study including data extraction, limitations of the study, references and all others. He was involved in drawing both the fig 1 and fig 2. The author read and approved the manuscript.

OS is a MBBS graduate from Sindh Medical College - Dow University of Health Sciences, Karachi, Pakistan.

Email address: ovaisshafi@gmail.com

\section{Corresponding author: OS}

Correspondence to Ovais Shafi

2. Ghazia Siddiqui (GS) is also the author of the manuscript and was involved in the writing, editing, and revision of the manuscript. GS also contributed to drawing the findings and interpretation of the data. She also contributed to all aspects of the results.

Her work also includes adherence of the study to relevant PRISMA guidelines, she also contributed to drawing both the fig 1 and fig 2. GS audited data extraction and limitations of the study. She critically audited references and gave important input towards adding additional references. GS is a MBBS graduate from Sindh Medical College - Jinnah Sindh Medical University, Karachi, Pakistan.

Ovais Shafi (OS) and Ghazia Siddiqui (GS) both are the authors of this research study. The work and contributions of both authors have been described in detail. The authors read and approve the manuscript. 


\section{References:}

1. Wirsching HG, Galanis E, Weller M. Glioblastoma. Handb Clin Neurol. 2016;134:381-97. doi: 10.1016/B978-0-12-802997-8.00023-2. PMID: 26948367.

2. Urbańska K, Sokołowska J, Szmidt M, Sysa P. Glioblastoma multiforme - an overview. Contemp Oncol (Pozn). 2014;18(5):307-312. doi:10.5114/wo.2014.40559

3. Mao H, Lebrun DG, Yang J, Zhu VF, Li M. Deregulated signaling pathways in glioblastoma multiforme: molecular mechanisms and therapeutic targets. Cancer Invest. 2012 Jan;30(1):48-56. doi: 10.3109/07357907.2011.630050. PMID: 22236189; PMCID: PMC3799884.

4. Davis ME. Glioblastoma: Overview of Disease and Treatment. Clin J Oncol Nurs. 2016;20(5 Suppl):S2-S8. doi:10.1188/16.CJON.S1.2-8

5. West AJ, Tsui V, Stylli SS, Nguyen HPT, Morokoff AP, Kaye AH, Luwor RB. The role of interleukin-6STAT3 signalling in glioblastoma. Oncol Lett. 2018 Oct;16(4):4095-4104. doi: 10.3892/ol.2018.9227. Epub 2018 Jul 27. PMID: 30250528; PMCID: PMC6144698.

6. Weis J, Schönrock LM, Züchner SL, Lie DC, Sure U, Schul C, Stögbauer F, Ringelstein EB, Halfter H. CNTF and its receptor subunits in human gliomas. J Neurooncol. 1999;44(3):243-53. doi: 10.1023/a:1006303221064. PMID: 10720204.

7. Peñuelas S, Anido J, Prieto-Sánchez RM, Folch G, Barba I, Cuartas I, García-Dorado D, Poca MA, Sahuquillo J, Baselga J, Seoane J. TGF-beta increases glioma-initiating cell self-renewal through the induction of LIF in human glioblastoma. Cancer Cell. 2009 Apr 7;15(4):315-27. doi: 10.1016/j.ccr.2009.02.011. PMID: 19345330.

8. Lu J, Ksendzovsky A, Yang C, et al. CNTF receptor subunit a as a marker for glioma tumor-initiating cells and tumor grade: laboratory investigation. J Neurosurg. 2012;117(6):1022-1031. doi:10.3171/2012.9.JNS1212

9. Halfter H, Kremerskothen J, Weber J, Hacker-Klom U, Barnekow A, Ringelstein EB, Stögbauer F. Growth inhibition of newly established human glioma cell lines by leukemia inhibitory factor. $\mathrm{J}$ Neurooncol. 1998 Aug;39(1):1-18. doi: 10.1023/a:1005901423332. PMID: 9760066.

10. Ardizzone A, Scuderi SA, Giuffrida D, Colarossi C, Puglisi C, Campolo M, Cuzzocrea S, Esposito E, Paterniti I. Role of Fibroblast Growth Factors Receptors (FGFRs) in Brain Tumors, Focus on Astrocytoma and Glioblastoma. Cancers (Basel). 2020 Dec 18;12(12):3825. doi: 10.3390/cancers12123825. PMID: 33352931; PMCID: PMC7766440.

11. Loilome W, Joshi AD, ap Rhys CM, Piccirillo S, Vescovi AL, Gallia GL, Riggins GJ. Glioblastoma cell growth is suppressed by disruption of Fibroblast Growth Factor pathway signaling. J Neurooncol. 2009 Sep;94(3):359-66. doi: 10.1007/s11060-009-9885-5. Epub 2009 Apr 2. Erratum in: J Neurooncol. 2010 May;97(3):459. Angelo, Vescovi L [corrected to Vescovi, Angelo L]. PMID: 19340397.

12. Jimenez-Pascual A, Siebzehnrubl FA. Fibroblast Growth Factor Receptor Functions in Glioblastoma. Cells. 2019;8(7):715. Published 2019 Jul 13. doi:10.3390/cells8070715 
13. Gonzalez AM, Berry M, Maher PA, Logan A, Baird A. A comprehensive analysis of the distribution of FGF-2 and FGFR1 in the rat brain. Brain Res. 1995 Dec 1;701(1-2):201-26. doi: 10.1016/00068993(95)01002-x. PMID: 8925285.

14. Miyake A, Hattori Y, Ohta M, Itoh N. Rat oligodendrocytes and astrocytes preferentially express fibroblast growth factor receptor-2 and -3 mRNAs. J Neurosci Res. 1996 Sep 1;45(5):534-41. doi: 10.1002/(SICl)1097-4547(19960901)45:5<534::AID-JNR3>3.0.CO;2-D. PMID: 8875318.

15. Ohashi R, Matsuda Y, Ishiwata T, Naito Z. Downregulation of fibroblast growth factor receptor 2 and its isoforms correlates with a high proliferation rate and poor prognosis in high-grade glioma. Oncol Rep. 2014 Sep;32(3):1163-9. doi: 10.3892/or.2014.3283. Epub 2014 Jun 23. PMID: 24968791.

16. Oldrini B, Hsieh WY, Erdjument-Bromage H, Codega P, Carro MS, Curiel-García A, Campos C, Pourmaleki M, Grommes C, Vivanco I, Rohle D, Bielski CM, Taylor BS, Hollmann TJ, Rosenblum M, Tempst P, Blenis J, Squatrito M, Mellinghoff IK. EGFR feedback-inhibition by Ran-binding protein 6 is disrupted in cancer. Nat Commun. 2017 Dec 11;8(1):2035. doi: 10.1038/s41467-017-02185-w. PMID: 29229958; PMCID: PMC5725448.

17. Heimberger AB, Hlatky R, Suki D, Yang D, Weinberg J, Gilbert M, Sawaya R, Aldape K. Prognostic effect of epidermal growth factor receptor and EGFRvIll in glioblastoma multiforme patients. Clin Cancer Res. 2005 Feb 15;11(4):1462-6. doi: 10.1158/1078-0432.CCR-04-1737. PMID: 15746047.

18. Ou A, Ott M, Fang D, Heimberger AB. The Role and Therapeutic Targeting of JAK/STAT Signaling in Glioblastoma. Cancers (Basel). 2021 Jan 24;13(3):437. doi: 10.3390/cancers13030437. PMID: 33498872; PMCID: PMC7865703.

19. Puram SV, Yeung CM, Jahani-Asl A, Lin C, de la Iglesia N, Konopka G, Jackson-Grusby L, Bonni A. STAT3-iNOS Signaling Mediates EGFRvIII-Induced Glial Proliferation and Transformation. J Neurosci. 2012 Jun 6;32(23):7806-18. doi: 10.1523/JNEUROSCI.3243-11.2012. PMID: 22674257; PMCID: PMC3409246.

20. Bromberg JF, Wrzeszczynska MH, Devgan G, Zhao Y, Pestell RG, Albanese C, Darnell JE Jr. Stat3 as an oncogene. Cell. 1999 Aug 6;98(3):295-303. doi: 10.1016/s0092-8674(00)81959-5. Erratum in: Cell 1999 Oct 15;99(2):239. PMID: 10458605.

21. Lo HW, Cao X, Zhu H, Ali-Osman F. Constitutively activated STAT3 frequently coexpresses with epidermal growth factor receptor in high-grade gliomas and targeting STAT3 sensitizes them to Iressa and alkylators. Clin Cancer Res. 2008 Oct 1;14(19):6042-54. doi: 10.1158/1078-0432.CCR-074923. PMID: 18829483; PMCID: PMC2707832.

22. Shao H, Cheng HY, Cook RG, Tweardy DJ. Identification and characterization of signal transducer and activator of transcription 3 recruitment sites within the epidermal growth factor receptor. Cancer Res. 2003 Jul 15;63(14):3923-30. PMID: 12873986.

23. Kim JE, Patel M, Ruzevick J, Jackson CM, Lim M. STAT3 Activation in Glioblastoma: Biochemical and Therapeutic Implications. Cancers (Basel). 2014 Feb 10;6(1):376-95. doi: 10.3390/cancers6010376. PMID: 24518612; PMCID: PMC3980601. 
24. Sang Y, Li Y, Song L, Alvarez AA, Zhang W, Lv D, Tang J, Liu F, Chang Z, Hatakeyama S, Hu B, Cheng SY, Feng H. TRIM59 Promotes Gliomagenesis by Inhibiting TC45 Dephosphorylation of STAT3. Cancer Res. 2018 Apr 1;78(7):1792-1804. doi: 10.1158/0008-5472.CAN-17-2774. Epub 2018 Jan 31. PMID: 29386185; PMCID: PMC5882560.

25. Wu J, Feng X, Zhang B, Li J, Xu X, Liu J, Wang X, Wang J, Tong X. Blocking the bFGF/STAT3 interaction through specific signaling pathways induces apoptosis in glioblastoma cells. J Neurooncol. 2014 Oct;120(1):33-41. doi: 10.1007/s11060-014-1529-8. Epub 2014 Jul 22. PMID: 25048528.

26. Xu Y, Li Z, Zhang C, Zhang S, Ji Y, Chen F. Knockdown of PKC $\varepsilon$ expression inhibits growth, induces apoptosis and decreases invasiveness of human glioma cells partially through Stat3. J Mol Neurosci. 2015 Jan;55(1):21-31. doi: 10.1007/s12031-014-0341-4. Epub 2014 Jun 4. PMID: 24888992.

27. Weissenberger J, Loeffler S, Kappeler A, Kopf M, Lukes A, Afanasieva TA, Aguzzi A, Weis J. IL-6 is required for glioma development in a mouse model. Oncogene. 2004 Apr 22;23(19):3308-16. doi: 10.1038/sj.onc.1207455. PMID: 15064729.

28. Liu Q, Li G, Li R, Shen J, He Q, Deng L, Zhang C, Zhang J. IL-6 promotion of glioblastoma cell invasion and angiogenesis in U251 and T98G cell lines. J Neurooncol. 2010 Nov;100(2):165-76. doi: 10.1007/s11060-010-0158-0. Epub 2010 Apr 2. PMID: 20361349.

29. Lee J, Son MJ, Woolard K, et al. Epigenetic-mediated dysfunction of the bone morphogenetic protein pathway inhibits differentiation of glioblastoma-initiating cells. Cancer Cell. 2008;13(1):69-80. doi:10.1016/j.ccr.2007.12.005

30. Xi G, Best B, Mania-Farnell B, James CD, Tomita T. Therapeutic Potential for Bone Morphogenetic Protein 4 in Human Malignant Glioma. Neoplasia. 2017;19(4):261-270. doi:10.1016/j.neo.2017.01.006

31. Sachdeva R, Wu M, Johnson K, Kim H, Celebre A, Shahzad U, Graham MS, Kessler JA, Chuang JH, Karamchandani J, Bredel M, Verhaak R, Das S. BMP signaling mediates glioma stem cell quiescence and confers treatment resistance in glioblastoma. Sci Rep. 2019 Oct 10;9(1):14569. doi:

10.1038/s41598-019-51270-1. PMID: 31602000; PMCID: PMC6787003.

32. Rampazzo E, Dettin M, Maule F, Scabello A, Calvanese L, D'Auria G, Falcigno L, Porcù E, Zamuner A, Della Puppa A, Boso D, Basso G, Persano L. A synthetic BMP-2 mimicking peptide induces glioblastoma stem cell differentiation. Biochim Biophys Acta Gen Subj. 2017 Sep;1861(9):22822292. doi: 10.1016/j.bbagen.2017.07.001. Epub 2017 Jul 4. PMID: 28687190.

33. Lee J, Son MJ, Woolard K, et al. Epigenetic-mediated dysfunction of the bone morphogenetic protein pathway inhibits differentiation of glioblastoma-initiating cells. Cancer Cell. 2008;13(1):69-80. doi:10.1016/j.ccr.2007.12.005

34. Lino MM, Merlo A, Boulay JL. Notch signaling in glioblastoma: a developmental drug target? $B M C$ Med. 2010;8:72. Published 2010 Nov 15. doi:10.1186/1741-7015-8-72 
35. Bazzoni R, Bentivegna A. Role of Notch Signaling Pathway in Glioblastoma Pathogenesis. Cancers (Basel). 2019;11(3):292. Published 2019 Mar 1. doi:10.3390/cancers11030292

36. Gersey Z, Osiason AD, Bloom L, Shah S, Thompson JW, Bregy A, Agarwal N, Komotar RJ. Therapeutic Targeting of the Notch Pathway in Glioblastoma Multiforme. World Neurosurg. 2019 Nov;131:252263.e2. doi: 10.1016/j.wneu.2019.07.180. Epub 2019 Jul 31. PMID: 31376551.

37. Yahyanejad S, King H, Iglesias VS, Granton PV, Barbeau LM, van Hoof SJ, Groot AJ, Habets R, Prickaerts J, Chalmers AJ, Eekers DB, Theys J, Short SC, Verhaegen F, Vooijs M. NOTCH blockade combined with radiation therapy and temozolomide prolongs survival of orthotopic glioblastoma. Oncotarget. 2016 Jul 5;7(27):41251-41264. doi: 10.18632/oncotarget.9275. PMID: 27183910; PMCID: PMC5173056.

38. Hulleman E, Quarto M, Vernell R, et al. A role for the transcription factor HEY1 in glioblastoma. J Cell Mol Med. 2009;13(1):136-146. doi:10.1111/j.1582-4934.2008.00307.x

39. Liu H, Liu Z, Jiang B, Peng R, Ma Z, Lu J. SOX9 Overexpression Promotes Glioma Metastasis via Wnt/ $\beta$-Catenin Signaling. Cell Biochem Biophys. 2015 Sep;73(1):205-12. doi: 10.1007/s12013-0150647-z. PMID: 25716338.

40. Wang L, He S, Yuan J, Mao X, Cao Y, Zong J, Tu Y, Zhang Y. Oncogenic role of SOX9 expression in human malignant glioma. Med Oncol. 2012 Dec;29(5):3484-90. doi: 10.1007/s12032-012-0267-z. Epub 2012 Jun 20. PMID: 22714060.

41. de la Rocha AM, Sampron N, Alonso MM, Matheu A. Role of SOX family of transcription factors in central nervous system tumors. Am J Cancer Res. 2014;4(4):312-324. Published 2014 Jul 16.

42. de la Iglesia N, Puram SV, Bonni A. STAT3 regulation of glioblastoma pathogenesis. Curr Mol Med. 2009;9(5):580-590. doi:10.2174/156652409788488739

43. Piperi C, Papavassiliou KA, Papavassiliou AG. Pivotal Role of STAT3 in Shaping Glioblastoma Immune Microenvironment. Cells. 2019 Nov 6;8(11):1398. doi: 10.3390/cells8111398. PMID: 31698775; PMCID: PMC6912524.

44. Wang H, Zhang L, Zhang IY, Chen X, Da Fonseca A, Wu S, Ren H, Badie S, Sadeghi S, Ouyang M, Warden CD, Badie B. S100B promotes glioma growth through chemoattraction of myeloid-derived macrophages. Clin Cancer Res. 2013 Jul 15;19(14):3764-75. doi: 10.1158/1078-0432.CCR-12-3725. Epub 2013 May 29. PMID: 23719262; PMCID: PMC3725731.

45. Siegel PM, Massagué J. Cytostatic and apoptotic actions of TGF-beta in homeostasis and cancer. Nat Rev Cancer. 2003 Nov;3(11):807-21. doi: 10.1038/nrc1208. PMID: 14557817.

46. Han J, Alvarez-Breckenridge CA, Wang QE, Yu J. TGF- $\beta$ signaling and its targeting for glioma treatment. Am J Cancer Res. 2015;5(3):945-955. Published 2015 Feb 15.

47. Jin X, Yin J, Kim SH, Sohn YW, Beck S, Lim YC, Nam DH, Choi YJ, Kim H. EGFR-AKT-Smad signaling promotes formation of glioma stem-like cells and tumor angiogenesis by ID3-driven cytokine induction. Cancer Res. 2011 Nov 15;71(22):7125-34. doi: 10.1158/0008-5472.CAN-11-1330. Epub 2011 Oct 5. PMID: 21975932. 
48. Rodríguez-García A, Samsó P, Fontova P, Simon-Molas H, Manzano A, Castaño E, Rosa JL, MartinezOutshoorn U, Ventura F, Navarro-Sabaté À, Bartrons R. TGF- $\beta 1$ targets Smad, p38 MAPK, and PI3K/Akt signaling pathways to induce PFKFB3 gene expression and glycolysis in glioblastoma cells. FEBS J. 2017 Oct;284(20):3437-3454. doi: 10.1111/febs.14201. Epub 2017 Sep 10. PMID: 28834297.

49. Panicker SP, Raychaudhuri B, Sharma P, et al. p300- and Myc-mediated regulation of glioblastoma multiforme cell differentiation. Oncotarget. 2010;1(4):289-303. doi:10.18632/oncotarget.100801

50. Hulleman E, Quarto M, Vernell R, et al. A role for the transcription factor HEY1 in glioblastoma. J Cell Mol Med. 2009;13(1):136-146. doi:10.1111/j.1582-4934.2008.00307.x

51. Gaetani P, Hulleman E, Levi D, Quarto M, Scorsetti M, Helins K, Simonelli M, Colombo P, Baena y Rodriguez R. Expression of the transcription factor HEY1 in glioblastoma: a preliminary clinical study. Tumori. 2010 Jan-Feb;96(1):97-102. PMID: 20437865.

52. Tsung AJ, Guda MR, Asuthkar S, Labak CM, Purvis IJ, Lu Y, Jain N, Bach SE, Prasad DVR, Velpula KK. Methylation regulates HEY1 expression in glioblastoma. Oncotarget. 2017 Jul 4;8(27):44398-44409. doi: 10.18632/oncotarget.17897. PMID: 28574840; PMCID: PMC5546488.

53. Brun M, Jain S, Monckton EA, Godbout R. Nuclear Factor I Represses the Notch Effector HEY1 in Glioblastoma. Neoplasia. 2018 Oct;20(10):1023-1037. doi: 10.1016/j.neo.2018.08.007. Epub 2018 Sep 6. PMID: 30195713; PMCID: PMC6138789.

54. Narayanappa R, Rout P, Aithal MG, Chand AK. Aberrant expression of Notch1, HES1, and DTX1 genes in glioblastoma formalin-fixed paraffin-embedded tissues. Tumour Biol. 2016 May;37(5):6935-42. doi: 10.1007/s13277-015-4592-7. Epub 2015 Dec 11. PMID: 26662803.

55. Cenciarelli C, Marei HE, Zonfrillo M, Casalbore P, Felsani A, Giannetti S, Trevisi G, Althani A, Mangiola A. The interference of Notch1 target Hes1 affects cell growth, differentiation and invasiveness of glioblastoma stem cells through modulation of multiple oncogenic targets. Oncotarget. 2017 Mar 14;8(11):17873-17886. doi: 10.18632/oncotarget.15013. PMID: 28157712; PMCID: PMC5392293.

56. Haapa-Paananen S, Kiviluoto S, Waltari M, Puputti M, Mpindi JP, Kohonen P, Tynninen O, Haapasalo H, Joensuu H, Perälä M, Kallioniemi O. HES6 gene is selectively overexpressed in glioma and represents an important transcriptional regulator of glioma proliferation. Oncogene. 2012 Mar 8;31(10):1299-310. doi: 10.1038/onc.2011.316. Epub 2011 Jul 25. PMID: 21785461.

57. Liu ZH, Dai XM, Du B. Hes1: a key role in stemness, metastasis and multidrug resistance. Cancer Biol Ther. 2015;16(3):353-359. doi:10.1080/15384047.2015.1016662

58. Komada M. Sonic hedgehog signaling coordinates the proliferation and differentiation of neural stem/progenitor cells by regulating cell cycle kinetics during development of the neocortex. Congenit Anom (Kyoto). 2012 Jun;52(2):72-7. doi: 10.1111/j.1741-4520.2012.00368.x. PMID: 22639991.

59. Carballo GB, Honorato JR, de Lopes GPF, Spohr TCLSE. A highlight on Sonic hedgehog pathway. Cell Commun Signal. 2018;16(1):11. Published 2018 Mar 20. doi:10.1186/s12964-018-0220-7

60. Hung HC, Liu CC, Chuang JY, Su CL, Gean PW. Inhibition of Sonic Hedgehog Signaling Suppresses Glioma Stem-Like Cells Likely Through Inducing Autophagic Cell Death. Front Oncol. 2020 Jul 
24;10:1233. doi: 10.3389/fonc.2020.01233. PMID: 32793494; PMCID: PMC7393230.

61. Mariyath MPM, Shahi MH, Farheen S, Tayyab M, Khanam N, Ali A. Novel Homeodomain Transcription Factor Nkx2.2 in the Brain Tumor Development. Curr Cancer Drug Targets. 2020;20(5):335-340. doi: 10.2174/1568009618666180102111539. PMID: 29295693.

62. Filbin MG, Dabral SK, Pazyra-Murphy MF, Ramkissoon S, Kung AL, Pak E, Chung J, Theisen MA, Sun Y, Franchetti Y, Sun Y, Shulman DS, Redjal N, Tabak B, Beroukhim R, Wang Q, Zhao J, Dorsch M, Buonamici S, Ligon KL, Kelleher JF, Segal RA. Coordinate activation of Shh and PI3K signaling in PTEN-deficient glioblastoma: new therapeutic opportunities. Nat Med. 2013 Nov;19(11):1518-23. doi: 10.1038/nm.3328. Epub 2013 Sep 29. PMID: 24076665; PMCID: PMC3923315.

63. Schmitt MJ, Company C, Dramaretska Y, Barozzi I, Göhrig A, Kertalli S, Großmann M, Naumann H, Sanchez-Bailon MP, Hulsman D, Glass R, Squatrito M, Serresi M, Gargiulo G. Phenotypic Mapping of Pathologic Cross-Talk between Glioblastoma and Innate Immune Cells by Synthetic Genetic Tracing. Cancer Discov. 2021 Mar;11(3):754-777. doi: 10.1158/2159-8290.CD-20-0219. Epub 2020 Dec 23. PMID: 33361384.

64. Bajetto A, Thellung S, Dellacasagrande I, Pagano A, Barbieri F, Florio T. Cross talk between mesenchymal and glioblastoma stem cells: Communication beyond controversies. Stem Cells Trans/ Med. 2020;9(11):1310-1330. doi:10.1002/sctm.20-0161

65. Zanca C, Villa GR, Benitez JA, Thorne AH, Koga T, D'Antonio M, Ikegami S, Ma J, Boyer AD, Banisadr A, Jameson NM, Parisian AD, Eliseeva OV, Barnabe GF, Liu F, Wu S, Yang H, Wykosky J, Frazer KA, Verkhusha VV, Isaguliants MG, Weiss WA, Gahman TC, Shiau AK, Chen CC, Mischel PS, Cavenee WK, Furnari FB. Glioblastoma cellular cross-talk converges on NF-kB to attenuate EGFR inhibitor sensitivity. Genes Dev. 2017 Jun 15;31(12):1212-1227. doi: 10.1101/gad.300079.117. Epub 2017 Jul 19. PMID: 28724615; PMCID: PMC5558924.

66. Carballo, G.B., Honorato, J.R., de Lopes, G.P. et al.A highlight on Sonic hedgehog pathway. Cell Commun Signal 16, 11 (2018). https://doi.org/10.1186/s12964-018-0220-7

67. Hegge, B., Sjøttem, E. \& Mikkola, I. Generation of a PAX6 knockout glioblastoma cell line with changes in cell cycle distribution and sensitivity to oxidative stress. BMC Cancer18, 496 (2018). https://doi.org/10.1186/s12885-018-4394-6

68. Zhou YH, Wu X, Tan F, Shi YX, Glass T, Liu TJ, Wathen K, Hess KR, Gumin J, Lang F, Yung WK. PAX6 suppresses growth of human glioblastoma cells. J Neurooncol. 2005 Feb;71(3):223-9. doi: 10.1007/s11060-004-1720-4. PMID: 15735909.

69. Molofsky AV, Krencik R, Ullian EM, et al. Astrocytes and disease: a neurodevelopmental perspective [published correction appears in Genes Dev. 2012 Jul 1;26(13):1508. Krenick, Robert [corrected to Krencik, Robert]; Ullian, Erik [corrected to Ullian, Erik M]]. Genes Dev. 2012;26(9):891-907. doi:10.1101/gad.188326.112

70. Mayes DA, Hu Y, Teng Y, Siegel E, Wu X, Panda K, Tan F, Yung WK, Zhou YH. PAX6 suppresses the invasiveness of glioblastoma cells and the expression of the matrix metalloproteinase-2 gene. Cancer Res. 2006 Oct 15;66(20):9809-17. doi: 10.1158/0008-5472.CAN-05-3877. PMID: 17047041. 
71. Zhou, YH., Hu, Y., Mayes, D. et al.PAX6 suppression of glioma angiogenesis and the expression of vascular endothelial growth factor A. J Neurooncol 96, 191-200 (2010). https://doi.org/10.1007/s11060-009-9963-8

72. Gómez-López S, Wiskow O, Favaro R, Nicolis SK, Price DJ, Pollard SM, Smith A. Sox2 and Pax6 maintain the proliferative and developmental potential of gliogenic neural stem cells In vitro. Glia. 2011 Nov;59(11):1588-99. doi: 10.1002/glia.21201. Epub 2011 Jul 15. PMID: 21766338.

73. Simpson TI, Price DJ. Pax6; a pleiotropic player in development. Bioessays. 2002 Nov;24(11):104151. doi: 10.1002/bies.10174. PMID: 12386935.

74. Thakurela, S., Tiwari, N., Schick, S. et al.Mapping gene regulatory circuitry of Pax6 during neurogenesis. Cell Discov 2, 15045 (2016). https://doi.org/10.1038/celldisc.2015.45

75. Soubannier V, Stifani S. NF-kB Signalling in Glioblastoma. Biomedicines. 2017 Jun 9;5(2):29. doi: 10.3390/biomedicines5020029. PMID: 28598356; PMCID: PMC5489815.

76. Yan K, Yang K, Rich JN. The evolving landscape of glioblastoma stem cells. Curr Opin Neurol. 2013 Dec;26(6):701-7. doi: 10.1097/WC0.0000000000000032. PMID: 24152818; PMCID: PMC4031658.

77. Kirk E. Cahill, Ramin A. Morshed, Bakhtiar Yamini, Nuclear factor-kB in glioblastoma: insights into regulators and targeted therapy, Neuro-Oncology, Volume 18, Issue 3, June 2015, Pages 329339, https://doi.org/10.1093/neuonc/nov265

78. Fallon KB, Havlioglu N, Hamilton LH, Cheng TP, Carroll SL. Constitutive activation of the neuregulin$1 /$ erbB signaling pathway promotes the proliferation of a human peripheral neuroepithelioma cell line. J Neurooncol. 2004 Feb;66(3):273-84. doi: 10.1023/b:neon.0000014521.28294.84. PMID: 15015657.

79. Lin WW, Ou GY, Lin JZ, Yi SJ, Yao WC, Pan HC, Zhao WJ. Neuregulin 1 enhances cell adhesion molecule L1 like expression levels and promotes malignancy in human glioma. Oncol Lett. 2020 Jul;20(1):326-336. doi: 10.3892/ol.2020.11548. Epub 2020 Apr 21. PMID: 32565959; PMCID: PMC7285836.

80. Zhao WJ, Schachner M. Neuregulin 1 enhances cell adhesion molecule 11 expression in human glioma cells and promotes their migration as a function of malignancy. J Neuropathol Exp Neurol. 2013 Mar;72(3):244-55. doi: 10.1097/NEN.0b013e3182863dc5. PMID: 23399902.

81. Ritch PS, Carroll SL, Sontheimer H. Neuregulin-1 enhances survival of human astrocytic glioma cells. Glia. 2005 Aug 15;51(3):217-28. doi: 10.1002/glia.20197. PMID: 15812817; PMCID: PMC2548407.

82. von Achenbach C, Weller M, Szabo E. Epidermal growth factor receptor and ligand family expression and activity in glioblastoma. J Neurochem. 2018 Oct;147(1):99-109. doi: 10.1111/jnc.14538. Epub 2018 Aug 16. PMID: 29953622.

83. Kagalwala MN, Singh SK, Majumder S. Stemness is only a state of the cell. Cold Spring Harb Symp Quant Biol. 2008;73:227-34. doi: 10.1101/sqb.2008.73.042. Epub 2009 Jan 15. PMID: 19150961.

84. Lu T, Aron L, Zullo J, et al. REST and stress resistance in ageing and Alzheimer's disease. Nature. 2014;507(7493):448-454. doi:10.1038/nature13163 
85. Kamal MM, Sathyan P, Singh SK, Zinn PO, Marisetty AL, Liang S, Gumin J, El-Mesallamy HO, Suki D, Colman H, Fuller GN, Lang FF, Majumder S. REST regulates oncogenic properties of glioblastoma stem cells. Stem Cells. 2012 Mar;30(3):405-14. doi: 10.1002/stem.1020. Erratum in: Stem Cells. 2012 May;30(5):1049. PMID: 22228704; PMCID: PMC4039365.

86. Zhang D, Li Y, Wang R, Li Y, Shi P, Kan Z, Pang X. Inhibition of REST Suppresses Proliferation and Migration in Glioblastoma Cells. Int J Mol Sci. 2016 May 3;17(5):664. doi: 10.3390/ijms17050664. PMID: 27153061; PMCID: PMC4881490.

87. Marisetty AL, Lu L, Veo BL, et al. REST-DRD2 mechanism impacts glioblastoma stem cell-mediated tumorigenesis. Neuro Oncol. 2019;21(6):775-785. doi:10.1093/neuonc/noz030

88. Hwang JY, Zukin RS. REST, a master transcriptional regulator in neurodegenerative disease. Curr Opin Neurobiol. 2018;48:193-200. doi:10.1016/j.conb.2017.12.008

89. Thompson R, Chan C. NRSF and Its Epigenetic Effectors: New Treatments for Neurological Disease. Brain Sci. 2018;8(12):226. Published 2018 Dec 19. doi:10.3390/brainsci8120226

90. Mao H, Lebrun DG, Yang J, Zhu VF, Li M. Deregulated signaling pathways in glioblastoma multiforme: molecular mechanisms and therapeutic targets. Cancer Invest. 2012;30(1):48-56. doi:10.3109/07357907.2011.630050

91. Oliva, C.R., Halloran, B., Hjelmeland, A.B. et al.IGFBP6 controls the expansion of chemoresistant glioblastoma through paracrine IGF2/IGF-1R signaling. Cell Commun Signal 16, 61 (2018). https://doi.org/10.1186/s12964-018-0273-7

92. Wang, L., Liu, Z., Balivada, S. et al.Interleukin-1 $\beta$ and transforming growth factor- $\beta$ cooperate to induce neurosphere formation and increase tumorigenicity of adherent LN-229 glioma cells. Stem Cell Res Ther 3, 5 (2012). https://doi.org/10.1186/scrt96

93. Oliveira-Nunes, M.C., Assad Kahn, S., de Oliveira Barbeitas, A.L. et al.The availability of the embryonic TGF- $\beta$ protein Nodal is dynamically regulated during glioblastoma multiforme tumorigenesis. Cancer Cell Int 16, 46 (2016). https://doi.org/10.1186/s12935-016-0324-3

94. Wang, H., Pan, JQ., Luo, L. et al.NF-KB induces miR-148a to sustain TGF- $\beta /$ Smad signaling activation in glioblastoma. Mol Cancer 14, 2 (2015). https://doi.org/10.1186/1476-4598-14-2

95. Wen PY, Kesari S. Malignant gliomas in adults. N Engl J Med. 2008 Jul 31;359(5):492-507. doi: 10.1056/NEJMra0708126. Erratum in: N Engl J Med. 2008 Aug 21;359(8):877. PMID: 18669428.

96. Bierie B, Moses HL. TGF-beta and cancer. Cytokine Growth Factor Rev. 2006 Feb-Apr;17(1-2):29-40. doi: 10.1016/j.cytogfr.2005.09.006. Epub 2005 Nov 10. PMID: 16289860.

97. Park, J., Shim, JK., Yoon, SJ. et al.Transcriptome profiling-based identification of prognostic subtypes and multi-omics signatures of glioblastoma. Sci Rep 9, 10555 (2019). https://doi.org/10.1038/s41598-019-47066-y

98. Donaires FS, Godoy PR, Leandro GS, Puthier D, Sakamoto-Hojo ET. E2F transcription factors associated with up-regulated genes in glioblastoma. Cancer Biomark. 2017;18(2):199-208. doi: 10.3233/CBM-161628. PMID: 27983535. 
99. Orozco-Morales M, Sánchez-García FJ, Golán-Cancela I, Hernández-Pedro N, Costoya JA, de la Cruz VP, Moreno-Jiménez S, Sotelo J, Pineda B. RB mutation and RAS overexpression induce resistance to NK cell-mediated cytotoxicity in glioma cells. Cancer Cell Int. 2015 Jun 5;15:57. doi: 10.1186/s12935015-0209-x. PMID: 26146488; PMCID: PMC4491266.

100. Ip W, Shao W, Chiang YT, Jin T. The Wnt signaling pathway effector TCF7L2 is upregulated by insulin and represses hepatic gluconeogenesis. Am J Physiol Endocrinol Metab. 2012 Nov 1;303(9):E116676. doi: 10.1152/ajpendo.00249.2012. Epub 2012 Sep 11. PMID: 22967502; PMCID: PMC3492858.

101. Moreira S, Polena E, Gordon V, Abdulla S, Mahendram S, Cao J, Blais A, Wood GA, Dvorkin-Gheva A, Doble BW. A Single TCF Transcription Factor, Regardless of Its Activation Capacity, Is Sufficient for Effective Trilineage Differentiation of ESCs. Cell Rep. 2017 Sep 5;20(10):2424-2438. doi: 10.1016/j.celrep.2017.08.043. PMID: 28877475.

102. Doumpas N, Lampart F, Robinson MD, et al. TCF/LEF dependent and independent transcriptional regulation of Wnt/ $\beta$-catenin target genes. EMBO J. 2019;38(2):e98873. doi:10.15252/embj.201798873

103. Li, Q., Sakurai, Y., Ryu, T. et al.Expression of Rb2/p130 protein correlates with the degree of malignancy in gliomas. Brain Tumor Pathol 21, 121-125 (2004). https://doi.org/10.1007/BF02482187

104. Liu Z, Ge R, Zhou J, et al. Nuclear factor IX promotes glioblastoma development through transcriptional activation of Ezrin. Oncogenesis. 2020;9(4):39. Published 2020 Apr 14. doi:10.1038/s41389-020-0223-2

105. Liu Y, Zhang W. The role of HOPX in normal tissues and tumor progression. Biosci Rep. 2020;40(1):BSR20191953. doi:10.1042/BSR20191953

106. De Toni A, Zbinden M, Epstein JA, Ruiz i Altaba A, Prochiantz A, Caillé I. Regulation of survival in adult hippocampal and glioblastoma stem cell lineages by the homeodomain-only protein HOP. Neural Dev. 2008;3:13. Published 2008 May 28. doi:10.1186/1749-8104-3-13

107. Clement V, Sanchez P, de Tribolet N, Radovanovic I, Ruiz i Altaba A. HEDGEHOG-GLI1 signaling regulates human glioma growth, cancer stem cell self-renewal, and tumorigenicity [published correction appears in Curr Biol. 2007 Jan 23;17(2):192]. Curr Biol. 2007;17(2):165-172. doi:10.1016/j.cub.2006.11.033

108. Ferluga S, Debinski W. Ephs and Ephrins in malignant gliomas. Growth Factors. 2014;32(6):190-201. doi:10.3109/08977194.2014.985787

109. Ylivinkka, I., Sihto, H., Tynninen, O. et al.Motility of glioblastoma cells is driven by netrin-1 induced gain of stemness. J Exp Clin Cancer Res 36, 9 (2017). https://doi.org/10.1186/s13046-016-0482-0

110. Guichet PO, Bieche I, Teigell M, Serguera C, Rothhut B, Rigau V, Scamps F, Ripoll C, Vacher S, Taviaux S, Chevassus H, Duffau H, Mallet J, Susini A, Joubert D, Bauchet L, Hugnot JP. Cell death and neuronal differentiation of glioblastoma stem-like cells induced by neurogenic transcription factors. Glia. 2013 Feb;61(2):225-39. doi: 10.1002/glia.22429. Epub 2012 Oct 9. PMID: 23047160. 
111. Su Z, Zang T, Liu ML, Wang LL, Niu W, Zhang CL. Reprogramming the fate of human glioma cells to impede brain tumor development. Cell Death Dis. 2014 Oct 16;5(10):e1463. doi:

10.1038/cddis.2014.425. PMID: 25321470; PMCID: PMC4649522.

112. Wang $X$, Pei Z, Hossain A, Bai Y, Chen G. Transcription factor-based gene therapy to treat glioblastoma through direct neuronal conversion. Cancer Biol Med. 2021 Mar 23:j.issn.20953941.2020.0499. doi: 10.20892/j.issn.2095-3941.2020.0499. Epub ahead of print. PMID: 33755378.

113. Roccograndi L, Binder ZA, Zhang L, Aceto N, Zhang Z, Bentires-Alj M, Nakano I, Dahmane N, O'Rourke DM. SHP2 regulates proliferation and tumorigenicity of glioma stem cells. J Neurooncol. 2017 Dec;135(3):487-496. doi: 10.1007/s11060-017-2610-x. Epub 2017 Aug 29. PMID: 28852935.

114. Lawn S, Krishna N, Pisklakova A, et al. Neurotrophin signaling via TrkB and TrkC receptors promotes the growth of brain tumor-initiating cells. J Biol Chem. 2015;290(6):3814-3824. doi:10.1074/jbc.M114.599373

115. Duan S, Yuan G, Liu X, Ren R, Li J, Zhang W, Wu J, Xu X, Fu L, Li Y, Yang J, Zhang W, Bai R, Yi F, Suzuki K, Gao H, Esteban CR, Zhang C, Izpisua Belmonte JC, Chen Z, Wang X, Jiang T, Qu J, Tang F, Liu GH. PTEN deficiency reprogrammes human neural stem cells towards a glioblastoma stem celllike phenotype. Nat Commun. 2015 Dec 3;6:10068. doi: 10.1038/ncomms10068. PMID: 26632666; PMCID: PMC4686761.

116. Hu YT, Li BF, Zhang PJ, et al. Dbx2 exhibits a tumor-promoting function in hepatocellular carcinoma cell lines viaregulating Shh-Gli1 signaling. World J Gastroenterol. 2019;25(8):923-940. doi:10.3748/wjg.v25.i8.923

117. Chung HH, Lee CT, Hu JM, Chou YC, Lin YW, Shih YL. NKX6.1 Represses Tumorigenesis, Metastasis, and Chemoresistance in Colorectal Cancer. Int J Mol Sci. 2020 Jul 19;21(14):5106. doi: 10.3390/ijms21145106. PMID: 32707737; PMCID: PMC7404324.

118. Li HJ, Yu PN, Huang KY, Su HY, Hsiao TH, Chang CP, Yu MH, Lin YW. NKX6.1 functions as a metastatic suppressor through epigenetic regulation of the epithelial-mesenchymal transition. Oncogene. 2016 Apr 28;35(17):2266-78. doi: 10.1038/onc.2015.289. Epub 2015 Aug 10. PMID: $26257059 ;$ PMCID: PMC4855079.

119. Liao D. Emerging roles of the EBF family of transcription factors in tumor suppression. Mol Cancer Res. 2009 Dec;7(12):1893-901. doi: 10.1158/1541-7786.MCR-09-0229. Epub 2009 Dec 8. PMID: 19996307; PMCID: PMC5545892.

120. Melhuish TA, Kowalczyk I, Manukyan A, Zhang Y, Shah A, Abounader R, Wotton D. Myt1 and Myt1I transcription factors limit proliferation in GBM cells by repressing YAP1 expression. Biochim Biophys Acta Gene Regul Mech. 2018 Nov;1861(11):983-995. doi: 10.1016/j.bbagrm.2018.10.005. Epub 2018 Oct 10. PMID: 30312684; PMCID: PMC6203443.

121. Haapa-Paananen S, Kiviluoto S, Waltari M, Puputti M, Mpindi JP, Kohonen P, Tynninen O, Haapasalo $H$, Joensuu $H$, Perälä M, Kallioniemi O. HES6 gene is selectively overexpressed in glioma and represents an important transcriptional regulator of glioma proliferation. Oncogene. $2012 \mathrm{Mar}$ 8;31(10):1299-310. doi: 10.1038/onc.2011.316. Epub 2011 Jul 25. PMID: 21785461. 
122. Sangpairoj K, Vivithanaporn P, Apisawetakan S, Chongthammakun S, Sobhon P, Chaithirayanon K. RUNX1 Regulates Migration, Invasion, and Angiogenesis via p38 MAPK Pathway in Human Glioblastoma. Cell Mol Neurobiol. 2017 Oct;37(7):1243-1255. doi: 10.1007/s10571-016-0456-y. Epub 2016 Dec 24. PMID: 28012022.

123. Yamada D, Fujikawa K, Kawabe K, Furuta T, Nakada M, Takarada T. RUNX2 Promotes Malignant Progression in Glioma. Neurochem Res. 2018 Nov;43(11):2047-2054. doi: 10.1007/s11064-0182626-4. Epub 2018 Sep 10. PMID: 30203400.

124. Xiu MX, Liu YM, Kuang BH. The Role of DLLs in Cancer: A Novel Therapeutic Target. Onco Targets Ther. 2020 May 7;13:3881-3901. doi: 10.2147/OTT.S244860. PMID: 32440154; PMCID: PMC7213894.

125. El Hindy N, Keyvani K, Pagenstecher A, et al. Implications of DII4-Notch signaling activation in primary glioblastoma multiforme. Neuro Oncol. 2013;15(10):1366-1378. doi:10.1093/neuonc/not071

126. Stockhausen MT, Kristoffersen K, Poulsen HS. The functional role of Notch signaling in human gliomas. Neuro Oncol. 2010;12(2):199-211. doi:10.1093/neuonc/nop022

127. Arai H, Ikota H, Sugawara K, Nobusawa S, Hirato J, Nakazato Y. Nestin expression in brain tumors: its utility for pathological diagnosis and correlation with the prognosis of high-grade gliomas. Brain Tumor Pathol. 2012 Jul;29(3):160-7. doi: 10.1007/s10014-012-0081-5. Epub 2012 Feb 19. PMID: 22350668.

128. Jin X, Jin X, Jung JE, Beck S, Kim H. Cell surface Nestin is a biomarker for glioma stem cells. Biochem Biophys Res Commun. 2013 Apr 19;433(4):496-501. doi: 10.1016/j.bbrc.2013.03.021. Epub 2013 Mar 21. PMID: 23524267.

129. Matini AH, Mofidi Naeini M, Haddad Kashani H, Vakili Z. Evaluation of Nestin and EGFR in Patients with Glioblastoma Multiforme in a Public Hospital in Iran. Asian Pac J Cancer Prev. 2020 Oct 1;21(10):2889-2894. doi: 10.31557/APJCP.2020.21.10.2889. PMID: 33112545; PMCID: PMC7798165.

130. Sachdeva R, Wu M, Johnson K, Kim H, Celebre A, Shahzad U, Graham MS, Kessler JA, Chuang JH, Karamchandani J, Bredel M, Verhaak R, Das S. BMP signaling mediates glioma stem cell quiescence and confers treatment resistance in glioblastoma. Sci Rep. 2019 Oct 10;9(1):14569. doi: 10.1038/s41598-019-51270-1. PMID: 31602000; PMCID: PMC6787003.

131. Rampazzo E, Dettin M, Maule F, Scabello A, Calvanese L, D'Auria G, Falcigno L, Porcù E, Zamuner A, Della Puppa A, Boso D, Basso G, Persano L. A synthetic BMP-2 mimicking peptide induces glioblastoma stem cell differentiation. Biochim Biophys Acta Gen Subj. 2017 Sep;1861(9):22822292. doi: 10.1016/j.bbagen.2017.07.001. Epub 2017 Jul 4. PMID: 28687190.

132. Jiang $X$, Xing $H$, Kim TM, et al. Numb regulates glioma stem cell fate and growth by altering epidermal growth factor receptor and Skp1-Cullin-F-box ubiquitin ligase activity. Stem Cells. 2012;30(7):1313-1326. doi:10.1002/stem.1120

133. Euskirchen P, Skaftnesmo KO, Huszthy PC, Brekkå N, Bjerkvig R, Jacobs AH, Miletic H. NUMB does not impair growth and differentiation status of experimental gliomas. Exp Cell Res. 2011 Dec 
10;317(20):2864-73. doi: 10.1016/j.yexcr.2011.09.002. Epub 2011 Sep 12. PMID: 21939656.

134. Park NI, Guilhamon P, Desai K, McAdam RF, Langille E, O'Connor M, Lan X, Whetstone H, Coutinho FJ, Vanner RJ, Ling E, Prinos P, Lee L, Selvadurai H, Atwal G, Kushida M, Clarke ID, Voisin V, Cusimano MD, Bernstein M, Das S, Bader G, Arrowsmith CH, Angers S, Huang X, Lupien M, Dirks PB. ASCL1 Reorganizes Chromatin to Direct Neuronal Fate and Suppress Tumorigenicity of Glioblastoma Stem Cells. Cell Stem Cell. 2017 Aug 3;21(2):209-224.e7. doi: 10.1016/j.stem.2017.06.004. Epub 2017 Jul 14. Erratum in: Cell Stem Cell. 2017 Sep 7;21(3):411. PMID: 28712938.

135. Ray SK. The Transcription Regulator Krüppel-Like Factor 4 and Its Dual Roles of Oncogene in Glioblastoma and Tumor Suppressor in Neuroblastoma. For Immunopathol Dis Therap. 2016;7(12):127-139. doi: 10.1615/ForumImmunDisTher.2016017227. PMID: 28497005; PMCID: PMC5423539.

136. Cenci T, Martini M, Montano N, D'Alessandris QG, Falchetti ML, Annibali D, Savino M, Bianchi F, Pierconti F, Nasi S, Pallini R, Larocca LM. Prognostic relevance of c-Myc and BMl1 expression in patients with glioblastoma. Am J Clin Pathol. 2012 Sep;138(3):390-6. doi:

10.1309/AJCPRXHNJQLO09QA. PMID: 22912356.

137. Theodorou E, Dalembert G, Heffelfinger C, et al. A high throughput embryonic stem cell screen identifies Oct-2 as a bifunctional regulator of neuronal differentiation. Genes Dev. 2009;23(5):575588. doi:10.1101/gad.1772509

138. Tantin D. Oct transcription factors in development and stem cells: insights and mechanisms. Development. 2013 Jul;140(14):2857-66. doi: 10.1242/dev.095927. PMID: 23821033; PMCID: PMC3699277.

139. Oliveira Al, Anjo SI, Vieira de Castro J, Serra SC, Salgado AJ, Manadas B, Costa BM. Crosstalk between glial and glioblastoma cells triggers the "go-or-grow" phenotype of tumor cells. Cell Commun Signal. 2017 Oct 2;15(1):37. doi: 10.1186/s12964-017-0194-x. PMID: 28969644; PMCID: PMC5625790.

140. Kucheryavykh LY, Rolón-Reyes K, Kucheryavykh YV, et al. Glioblastoma development in mouse brain: general reduction of OCTs and mislocalization of OCT3 transporter and subsequent uptake of ASP $^{+}$substrate to the nuclei. J Neurosci Neuroeng. 2014;3(1):3-9. doi:10.1166/jnsne.2014.1091

141. Liu, J., Qiu, J., Zhang, Z. et al.SOX4 maintains the stemness of cancer cells via transcriptionally enhancing HDAC1 revealed by comparative proteomics study. Cell Biosci 11, 23 (2021). https://doi.org/10.1186/s13578-021-00539-y

142. Ikushima H, Todo T, Ino Y, Takahashi M, Saito N, Miyazawa K, Miyazono K. Glioma-initiating cells retain their tumorigenicity through integration of the Sox axis and Oct4 protein. J Biol Chem. 2011 Dec 2;286(48):41434-41441. doi: 10.1074/jbc.M111.300863. Epub 2011 Oct 10. PMID: 21987575; PMCID: PMC3308855.

143. Johansson E, Zhai Q, Zeng ZJ, Yoshida T, Funa K. Nuclear receptor TLX inhibits TGF- $\beta$ signaling in glioblastoma. Exp Cell Res. 2016 May 1;343(2):118-125. doi: 10.1016/j.yexcr.2016.03.028. Epub 2016 Apr 2. PMID: 27048878. 
144. Zou Y, Niu W, Qin S, Downes M, Burns DK, Zhang CL. The nuclear receptor TLX is required for gliomagenesis within the adult neurogenic niche. Mol Cell Biol. 2012 Dec;32(23):4811-20. doi: 10.1128/MCB.01122-12. Epub 2012 Oct 1. PMID: 23028043; PMCID: PMC3497606.

145. Lee Y, Lee JK, Ahn SH, Lee J, Nam DH. WNT signaling in glioblastoma and therapeutic opportunities. Lab Invest. 2016 Feb;96(2):137-50. doi: 10.1038/labinvest.2015.140. Epub 2015 Dec 7. PMID: 26641068.

146. Shevchenko V, Arnotskaya N, Korneyko M, Zaytsev S, Khotimchenko Y, Sharma H, Bryukhovetskiy I. Proteins of the Wnt signaling pathway as targets for the regulation of CD133+ cancer stem cells in glioblastoma. Oncol Rep. 2019 May;41(5):3080-3088. doi: 10.3892/or.2019.7043. Epub 2019 Mar 5. PMID: 30864699.

147. Tompa M, Kalovits F, Nagy A, Kalman B. Contribution of the Wnt Pathway to Defining Biology of Glioblastoma. Neuromolecular Med. 2018 Dec;20(4):437-451. doi: 10.1007/s12017-018-8514-x. Epub 2018 Sep 26. PMID: 30259273.

148. de la Rocha AM, Sampron N, Alonso MM, Matheu A. Role of SOX family of transcription factors in central nervous system tumors. Am J Cancer Res. 2014;4(4):312-324. Published 2014 Jul 16.

149. Higgins DM, Wang R, Milligan B, Schroeder M, Carlson B, Pokorny J, Cheshier SH, Meyer FB, Weissman IL, Sarkaria JN, Henley JR. Brain tumor stem cell multipotency correlates with nanog expression and extent of passaging in human glioblastoma xenografts. Oncotarget. 2013 May;4(5):792-801. doi: 10.18632/oncotarget.1059. PMID: 23801022; PMCID: PMC3742839.

150. Hovinga KE, Shimizu F, Wang R, Panagiotakos G, Van Der Heijden M, Moayedpardazi H, Correia AS, Soulet D, Major T, Menon J, Tabar V. Inhibition of notch signaling in glioblastoma targets cancer stem cells via an endothelial cell intermediate. Stem Cells. 2010 Jun;28(6):1019-29. doi: 10.1002/stem.429. PMID: 20506127; PMCID: PMC5532884.

151. Bazzoni R, Bentivegna A. Role of Notch Signaling Pathway in Glioblastoma Pathogenesis. Cancers (Basel). 2019 Mar 1;11(3):292. doi: 10.3390/cancers11030292. PMID: 30832246; PMCID: PMC6468848.

152. Lino, M.M., Merlo, A. \& Boulay, JL. Notch signaling in glioblastoma: a developmental drug target?. BMC Med8, 72 (2010). https://doi.org/10.1186/1741-7015-8-72

153. Hu, YY., Zheng, MH., Cheng, G. et al.Notch signaling contributes to the maintenance of both normal neural stem cells and patient-derived glioma stem cells. BMC Cancer 11, 82 (2011). https://doi.org/10.1186/1471-2407-11-82

154. Yi, L., Zhou, X., Li, T. et al.Notch1 signaling pathway promotes invasion, self-renewal and growth of glioma initiating cells via modulating chemokine system CXCL12/CXCR4. J Exp Clin Cancer Res 38, 339 (2019). https://doi.org/10.1186/s13046-019-1319-4

155. Galoczova, M., Coates, P. \& Vojtesek, B. STAT3, stem cells, cancer stem cells and p63. Cell Mol Biol Lett23, 12 (2018). https://doi.org/10.1186/s11658-018-0078-0

156. Kotliarova S, Pastorino S, Kovell LC, et al. Glycogen synthase kinase-3 inhibition induces glioma cell death through c-MYC, nuclear factor-kappaB, and glucose regulation. Cancer Res. 2008;68(16):6643- 
6651. doi:10.1158/0008-5472.CAN-08-0850

157. Proctor CJ, Gray DA. GSK3 and p53 - is there a link in Alzheimer's disease?. Mol Neurodegener. 2010;5:7. Published 2010 Jan 26. doi:10.1186/1750-1326-5-7

158. Kim WY, Snider WD. Functions of GSK-3 Signaling in Development of the Nervous System. Front Mol Neurosci. 2011 Nov 17;4:44. doi: 10.3389/fnmol.2011.00044. PMID: 22125510; PMCID: PMC3221276.

159. Kim YT, Hur EM, Snider WD, Zhou FQ. Role of GSK3 Signaling in Neuronal Morphogenesis. Front Mol Neurosci. 2011 Nov 23;4:48. doi: 10.3389/fnmol.2011.00048. PMID: 22131966; PMCID: PMC3222852.

160. Hur EM, Zhou FQ. GSK3 signalling in neural development. Nat Rev Neurosci. 2010 Aug;11(8):539-51. doi: 10.1038/nrn2870. PMID: 20648061; PMCID: PMC3533361.

161. Majewska E, Szeliga M. AKT/GSK3ß Signaling in Glioblastoma. Neurochem Res. 2017 Mar;42(3):918-924. doi: 10.1007/s11064-016-2044-4. Epub 2016 Aug 27. PMID: 27568206; PMCID: PMC5357492.

162. Domoto T, Uehara M, Bolidong D, Minamoto T. Glycogen Synthase Kinase $3 \beta$ in Cancer Biology and Treatment. Cells. 2020 Jun 3;9(6):1388. doi: 10.3390/cells9061388. PMID: 32503133; PMCID: PMC7349761.

163. Shafi, O. Inverse relationship between Alzheimer's disease and cancer, and other factors contributing to Alzheimer's disease: a systematic review. BMC Neuro/16, 236 (2016). https://doi.org/10.1186/s12883-016-0765-2

164. White CW 3rd, Fan X, Maynard JC, Wheatley EG, Bieri G, Couthouis J, Burlingame AL, Villeda SA. Agerelated loss of neural stem cell O-GIcNAc promotes a glial fate switch through STAT3 activation. Proc Natl Acad Sci U S A. 2020 Sep 8;117(36):22214-22224. doi: 10.1073/pnas.2007439117. Epub 2020 Aug 26. PMID: 32848054; PMCID: PMC7486730.

165. Sloan EA, Hilz S, Gupta R, Cadwell C, Ramani B, Hofmann J, Kline CN, Banerjee A, Reddy A, Oberheim Bush NA, Chang S, Braunstein S, Chang EF, Raffel C, Gupta N, Sun PP, Kim JYH, Moes G, Alva E, Li R, Bruggers CS, Alashari M, Wetmore C, Garg S, Dishop M, Van Ziffle J, Onodera C, Devine P, Grenert JP, Lee JC, Phillips JJ, Pekmezci M, Tihan T, Bollen AW, Berger MS, Costello JF, Perry A, Solomon DA. Gliomas arising in the setting of Li-Fraumeni syndrome stratify into two molecular subgroups with divergent clinicopathologic features. Acta Neuropathol. 2020 May;139(5):953-957. doi: 10.1007/s00401-020-02144-8. Epub 2020 Mar 10. PMID: 32157385; PMCID: PMC7183424.

166. Orr BA, Clay MR, Pinto EM, Kesserwan C. An update on the central nervous system manifestations of Li-Fraumeni syndrome. Acta Neuropathol. 2020 Apr;139(4):669-687. doi: 10.1007/s00401-01902055-3. Epub 2019 Aug 30. PMID: 31468188.

167. D'Angelo F, Ceccarelli M, Tala, Garofano L, Zhang J, Frattini V, Caruso FP, Lewis G, Alfaro KD, Bauchet L, Berzero G, Cachia D, Cangiano M, Capelle L, de Groot J, DiMeco F, Ducray F, Farah W, Finocchiaro G, Goutagny S, Kamiya-Matsuoka C, Lavarino C, Loiseau H, Lorgis V, Marras CE, McCutcheon I, Nam DH, Ronchi S, Saletti V, Seizeur R, Slopis J, Suñol M, Vandenbos F, Varlet P, Vidaud D, Watts C, Tabar 
V, Reuss DE, Kim SK, Meyronet D, Mokhtari K, Salvador H, Bhat KP, Eoli M, Sanson M, Lasorella A, lavarone A. The molecular landscape of glioma in patients with Neurofibromatosis 1. Nat Med. 2019 Jan;25(1):176-187. doi: 10.1038/s41591-018-0263-8. Epub 2018 Dec 10. PMID: 30531922; PMCID: PMC6857804.

168. Albers AC, Gutmann DH. Gliomas in patients with neurofibromatosis type 1. Expert Rev Neurother. 2009 Apr;9(4):535-9. doi: 10.1586/ern.09.4. PMID: 19344304.

169. Alexandru O, Horescu C, Sevastre AS, et al. Receptor tyrosine kinase targeting in glioblastoma: performance, limitations and future approaches. Contemp Oncol (Pozn). 2020;24(1):55-66. doi:10.5114/wo.2020.94726

170. Lee DY, Yeh TH, Emnett RJ, White CR, Gutmann DH. Neurofibromatosis-1 regulates neuroglial progenitor proliferation and glial differentiation in a brain region-specific manner. Genes Dev. 2010;24(20):2317-2329. doi:10.1101/gad.1957110

171. D'Angelo F, Ceccarelli M, Tala, Garofano L, Zhang J, Frattini V, Caruso FP, Lewis G, Alfaro KD, Bauchet L, Berzero G, Cachia D, Cangiano M, Capelle L, de Groot J, DiMeco F, Ducray F, Farah W, Finocchiaro G, Goutagny S, Kamiya-Matsuoka C, Lavarino C, Loiseau H, Lorgis V, Marras CE, McCutcheon I, Nam DH, Ronchi S, Saletti V, Seizeur R, Slopis J, Suñol M, Vandenbos F, Varlet P, Vidaud D, Watts C, Tabar V, Reuss DE, Kim SK, Meyronet D, Mokhtari K, Salvador H, Bhat KP, Eoli M, Sanson M, Lasorella A, lavarone A. The molecular landscape of glioma in patients with Neurofibromatosis 1. Nat Med. 2019 Jan;25(1):176-187. doi: 10.1038/s41591-018-0263-8. Epub 2018 Dec 10. PMID: 30531922; PMCID: PMC6857804.

172. Chen YH, Gianino SM, Gutmann DH. Neurofibromatosis-1 regulation of neural stem cell proliferation and multilineage differentiation operates through distinct RAS effector pathways. Genes Dev. 2015;29(16):1677-1682. doi:10.1101/gad.261677.115

173. Wang Y, Kim E, Wang X, Novitch BG, Yoshikawa K, Chang LS, Zhu Y. ERK inhibition rescues defects in fate specification of Nf1-deficient neural progenitors and brain abnormalities. Cell. 2012 Aug 17;150(4):816-30. doi: 10.1016/j.cell.2012.06.034. PMID: 22901811; PMCID: PMC3427010.

174. Fisher MJ, Jones DTW, Li Y, Guo X, Sonawane PS, Waanders AJ, Phillips JJ, Weiss WA, Resnick AC, Gosline S, Banerjee J, Guinney J, Gnekow A, Kandels D, Foreman NK, Korshunov A, Ryzhova M, Massimi L, Gururangan S, Kieran MW, Wang Z, Fouladi M, Sato M, Øra I, Holm S, Markham SJ, Beck P, Jäger N, Wittmann A, Sommerkamp AC, Sahm F, Pfister SM, Gutmann DH. Integrated molecular and clinical analysis of low-grade gliomas in children with neurofibromatosis type 1 (NF1). Acta Neuropathol. 2021 Apr;141(4):605-617. doi: 10.1007/s00401-021-02276-5. Epub 2021 Feb 14. PMID: 33585982.

175. Jecrois ES, Zheng W, Bornhorst M, Li Y, Treisman DM, Muguyo D, Huynh S, Andrew SF, Wang Y, Jiang J, Pierce BR, Mao H, Krause MK, Friend A, Nadal-Nicolas F, Stasheff SF, Li W, Zong H, Packer RJ, Zhu Y. Treatment during a developmental window prevents NF1-associated optic pathway gliomas by targeting Erk-dependent migrating glial progenitors. Dev Cell. 2021 Oct 25;56(20):2871-2885.e6. doi: 10.1016/j.devcel.2021.08.004. Epub 2021 Aug 23. PMID: 34428430. 
176. Shibahara I, Sonoda Y, Suzuki H, Mayama A, Kanamori M, Saito R, Suzuki Y, Mashiyama S, Uenohara $\mathrm{H}$, Watanabe M, Kumabe T, Tominaga T. Glioblastoma in neurofibromatosis 1 patients without IDH1, BRAF V600E, and TERT promoter mutations. Brain Tumor Pathol. 2018 Jan;35(1):10-18. doi: 10.1007/s10014-017-0302-z. Epub 2017 Nov 14. PMID: 29138945.

177. Aranha MM, Solá S, Low WC, Steer CJ, Rodrigues CM. Caspases and p53 modulate FOX03A/Id1 signaling during mouse neural stem cell differentiation. J Cell Biochem. 2009 Jul 1;107(4):748-58. doi: 10.1002/jcb.22172. PMID: 19415678.

178. Zhang $X$, Rielland M, Yalcin S, Ghaffari S. Regulation and function of FoxO transcription factors in normal and cancer stem cells: what have we learned? Curr Drug Targets. 2011 Aug;12(9):1267-83. doi: 10.2174/138945011796150325. PMID: 21443463.

179. Wang Y, Zhou Y, Graves DT. FOXO transcription factors: their clinical significance and regulation. Biomed Res Int. 2014;2014:925350. doi: 10.1155/2014/925350. Epub 2014 Apr 3. PMID: 24864265; PMCID: PMC4016844.

180. Qian Z, Ren L, Wu D, Yang X, Zhou Z, Nie Q, Jiang G, Xue S, Weng W, Qiu Y, Lin Y. Overexpression of FoxO3a is associated with glioblastoma progression and predicts poor patient prognosis. Int $\mathrm{J}$ Cancer. 2017 Jun 15;140(12):2792-2804. doi: 10.1002/ijc.30690. Epub 2017 Apr 3. PMID: 28295288.

181. Lau CJ, Koty Z, Nalbantoglu J. Differential response of glioma cells to FOX01-directed therapy. Cancer Res. 2009 Jul 1;69(13):5433-40. doi: 10.1158/0008-5472.CAN-08-4540. Epub 2009 Jun 23. PMID: 19549905.

182. Sunayama J, Sato A, Matsuda K, Tachibana K, Watanabe E, Seino S, Suzuki K, Narita Y, Shibui S, Sakurada K, Kayama T, Tomiyama A, Kitanaka C. FoxO3a functions as a key integrator of cellular signals that control glioblastoma stem-like cell differentiation and tumorigenicity. Stem Cells. 2011 Sep;29(9):1327-37. doi: 10.1002/stem.696. PMID: 21793107.

183. Wang L, Wang J, Jin T, Zhou Y, Chen Q. FoxG1 facilitates proliferation and inhibits differentiation by downregulating FoxO/Smad signaling in glioblastoma. Biochem Biophys Res Commun. 2018 Sep 26;504(1):46-53. doi: 10.1016/j.bbrc.2018.08.118. Epub 2018 Aug 29. PMID: 30172378.

184. Xiong Y, Zhang Y, Xiong S, Williams-Villalobo AE. A Glance of p53 Functions in Brain Development, Neural Stem Cells, and Brain Cancer. Biology (Basel). 2020 Sep 11;9(9):285. doi: 10.3390/biology9090285. PMID: 32932978; PMCID: PMC7564678.

185. Takahashi R, Giannini C, Sarkaria JN, et al. p53 isoform profiling in glioblastoma and injured brain. Oncogene. 2013;32(26):3165-3174. doi:10.1038/onc.2012.322

186. Marin Navarro A, Pronk RJ, van der Geest AT, Oliynyk G, Nordgren A, Arsenian-Henriksson M, Falk A, Wilhelm M. p53 controls genomic stability and temporal differentiation of human neural stem cells and affects neural organization in human brain organoids. Cell Death Dis. 2020 Jan 23;11(1):52. doi: 10.1038/s41419-019-2208-7. PMID: 31974372; PMCID: PMC6978389.

187. Zhang Y, Dube C, Gibert M Jr, et al. The p53 Pathway in Glioblastoma. Cancers (Basel). 2018;10(9):297. Published 2018 Sep 1. doi:10.3390/cancers10090297 
188. Nagpal J, Jamoona A, Gulati ND, Mohan A, Braun A, Murali R, Jhanwar-Uniyal M. Revisiting the role of p53 in primary and secondary glioblastomas. Anticancer Res. 2006 Nov-Dec;26(6C):4633-9. PMID: 17214319.

189. Zhao R, Choi BY, Lee MH, Bode AM, Dong Z. Implications of Genetic and Epigenetic Alterations of CDKN2A (p16(INK4a)) in Cancer. EBioMedicine. 2016;8:30-39. doi:10.1016/j.ebiom.2016.04.017

190. Biernat W, Kleihues P, Yonekawa Y, Ohgaki H. Amplification and overexpression of MDM2 in primary (de novo) glioblastomas. J Neuropathol Exp Neurol. 1997 Feb;56(2):180-5. doi: 10.1097/00005072199702000-00009. PMID: 9034372.

191. Stark AM, Hugo HH, Witzel P, Mihajlovic Z, Mehdorn HM. Age-related expression of p53, Mdm2, EGFR and Msh2 in glioblastoma multiforme. Zentralbl Neurochir. 2003;64(1):30-6. doi: 10.1055/s-200337149. PMID: 12582944.

192. Ferguson KL, Slack RS. The Rb pathway in neurogenesis. Neuroreport. 2001 Jul 3;12(9):A55-62. doi: 10.1097/00001756-200107030-00001. PMID: 11435948.

193. Hulleman E, Helin K. Molecular mechanisms in gliomagenesis. Adv Cancer Res. 2005;94:1-27. doi: 10.1016/S0065-230X(05)94001-3. PMID: 16095998.

194. Ferguson KL, Vanderluit JL, Hébert JM, et al. Telencephalon-specific Rb knockouts reveal enhanced neurogenesis, survival and abnormal cortical development. EMBO J. 2002;21(13):3337-3346. doi:10.1093/emboj/cdf338

195. Cen L, Carlson BL, Schroeder MA, Ostrem JL, Kitange GJ, Mladek AC, Fink SR, Decker PA, Wu W, Kim JS, Waldman T, Jenkins RB, Sarkaria JN. p16-Cdk4-Rb axis controls sensitivity to a cyclin-dependent kinase inhibitor PD0332991 in glioblastoma xenograft cells. Neuro Oncol. 2012 Jul;14(7):870-81. doi: 10.1093/neuonc/nos114. Epub 2012 Jun 18. PMID: 22711607; PMCID: PMC3379801.

196. Sirui Ma, Soumon Rudra, Jian L Campian, Sonika Dahiya, Gavin P Dunn, Tanner Johanns, Michael Goldstein, Albert H Kim, Jiayi Huang, Prognostic impact of CDKN2A/B deletion, TERT mutation, and EGFR amplification on histological and molecular IDH-wildtype glioblastoma, Neuro-Oncology Advances, Volume 2, Issue 1, January-December 2020, vdaa126, https://doi.org/10.1093/noajnl/vdaa126

197. Ghasimi S, Wibom C, Dahlin AM, Brännström T, Golovleva I, Andersson U, Melin B. Genetic risk variants in the CDKN2A/B, RTEL1 and EGFR genes are associated with somatic biomarkers in glioma. J Neurooncol. 2016 May;127(3):483-92. doi: 10.1007/s11060-016-2066-4. Epub 2016 Feb 2. PMID: 26839018; PMCID: PMC4835517.

198. Karpel-Massler G, Nguyen TTT, Shang E, Siegelin MD. Novel IDH1-Targeted Glioma Therapies. CNS Drugs. 2019 Dec;33(12):1155-1166. doi: 10.1007/s40263-019-00684-6. PMID: 31768950; PMCID: PMC7027940.

199. Gorovets D, Kannan K, Shen R, Kastenhuber ER, Islamdoust N, Campos C, Pentsova E, Heguy A, Jhanwar SC, Mellinghoff IK, Chan TA, Huse JT. IDH mutation and neuroglial developmental features define clinically distinct subclasses of lower grade diffuse astrocytic glioma. Clin Cancer Res. 2012 May 1;18(9):2490-501. doi: 10.1158/1078-0432.CCR-11-2977. Epub 2012 Mar 13. PMID: 22415316. 
200. Han S, Liu Y, Cai SJ, Qian M, Ding J, Larion M, Gilbert MR, Yang C. IDH mutation in glioma: molecular mechanisms and potential therapeutic targets. Br J Cancer. 2020 May;122(11):1580-1589. doi: 10.1038/s41416-020-0814-x. Epub 2020 Apr 15. PMID: 32291392; PMCID: PMC7250901.

201. Watanabe T, Nobusawa S, Kleihues P, Ohgaki H. IDH1 mutations are early events in the development of astrocytomas and oligodendrogliomas. Am J Pathol. 2009;174(4):1149-1153. doi:10.2353/ajpath.2009.080958

202. Simon M, Hosen I, Gousias K, Rachakonda S, Heidenreich B, Gessi M, Schramm J, Hemminki K, Waha A, Kumar R. TERT promoter mutations: a novel independent prognostic factor in primary glioblastomas. Neuro Oncol. 2015 Jan;17(1):45-52. doi: 10.1093/neuonc/nou158. Epub 2014 Aug 18. PMID: 25140036; PMCID: PMC4483052.

203. Nonoguchi N, Ohta T, Oh JE, Kim YH, Kleihues P, Ohgaki H. TERT promoter mutations in primary and secondary glioblastomas. Acta Neuropathol. 2013 Dec;126(6):931-7. doi: 10.1007/s00401-013-11630. Epub 2013 Aug 17. PMID: 23955565.

204. Olympios N, Gilard V, Marguet F, Clatot F, Di Fiore F, Fontanilles M. TERTPromoter Alterations in Glioblastoma: A Systematic Review. Cancers (Basel). 2021 Mar 8;13(5):1147. doi: 10.3390/cancers13051147. PMID: 33800183; PMCID: PMC7962450.

205. Baumgarten P, Harter PN, Tönjes M, Capper D, Blank AE, Sahm F, von Deimling A, Kolluru V, Schwamb B, Rabenhorst U, Starzetz T, Kögel D, Rieker RJ, Plate KH, Ohgaki H, Radlwimmer B, Zörnig M, Mittelbronn M. Loss of FUBP1 expression in gliomas predicts FUBP1 mutation and is associated with oligodendroglial differentiation, IDH1 mutation and 1p/19q loss of heterozygosity. Neuropathol Appl Neurobiol. 2014 Feb;40(2):205-16. doi: 10.1111/nan.12088. PMID: 24117486.

206. Jiao Y, Killela PJ, Reitman ZJ, Rasheed AB, Heaphy CM, de Wilde RF, Rodriguez FJ, Rosemberg S, Oba-Shinjo SM, Nagahashi Marie SK, Bettegowda C, Agrawal N, Lipp E, Pirozzi C, Lopez G, He Y, Friedman H, Friedman AH, Riggins GJ, Holdhoff M, Burger P, McLendon R, Bigner DD, Vogelstein B, Meeker AK, Kinzler KW, Papadopoulos N, Diaz LA, Yan H. Frequent ATRX, CIC, FUBP1 and IDH1 mutations refine the classification of malignant gliomas. Oncotarget. 2012 Jul;3(7):709-22. doi: 10.18632/oncotarget.588. PMID: 22869205; PMCID: PMC3443254.

207. Chen R, Smith-Cohn M, Cohen AL, Colman H. Glioma Subclassifications and Their Clinical Significance. Neurotherapeutics. 2017;14(2):284-297. doi:10.1007/s13311-017-0519-x

208. Furnari FB, Fenton T, Bachoo RM, Mukasa A, Stommel JM, Stegh A, Hahn WC, Ligon KL, Louis DN, Brennan C, Chin L, DePinho RA, Cavenee WK. Malignant astrocytic glioma: genetics, biology, and paths to treatment. Genes Dev. 2007 Nov 1;21(21):2683-710. doi: 10.1101/gad.1596707. PMID: 17974913.

209. Doucette T, Rao G, Rao A, Shen L, Aldape K, Wei J, Dziurzynski K, Gilbert M, Heimberger AB. Immune heterogeneity of glioblastoma subtypes: extrapolation from the cancer genome atlas. Cancer Immunol Res. 2013 Aug;1(2):112-22. doi: 10.1158/2326-6066.CIR-13-0028. PMID: 24409449; PMCID: PMC3881271. 
210. Verhaak RG, Hoadley KA, Purdom E, Wang V, Qi Y, Wilkerson MD, Miller CR, Ding L, Golub T, Mesirov JP, Alexe G, Lawrence M, O'Kelly M, Tamayo P, Weir BA, Gabriel S, Winckler W, Gupta S, Jakkula L, Feiler HS, Hodgson JG, James CD, Sarkaria JN, Brennan C, Kahn A, Spellman PT, Wilson RK, Speed TP, Gray JW, Meyerson M, Getz G, Perou CM, Hayes DN; Cancer Genome Atlas Research Network. Integrated genomic analysis identifies clinically relevant subtypes of glioblastoma characterized by abnormalities in PDGFRA, IDH1, EGFR, and NF1. Cancer Cell. 2010 Jan 19;17(1):98-110. doi: 10.1016/j.ccr.2009.12.020. PMID: 20129251; PMCID: PMC2818769.

211. Fedele M, Cerchia L, Pegoraro S, Sgarra R, Manfioletti G. Proneural-Mesenchymal Transition: Phenotypic Plasticity to Acquire Multitherapy Resistance in Glioblastoma. Int J Mol Sci. 2019 Jun 4;20(11):2746. doi: 10.3390/ijms20112746. PMID: 31167470; PMCID: PMC6600373.

212. Sandmann T, Bourgon R, Garcia J, Li C, Cloughesy T, Chinot OL, Wick W, Nishikawa R, Mason W, Henriksson R, Saran F, Lai A, Moore N, Kharbanda S, Peale F, Hegde P, Abrey LE, Phillips HS, Bais C. Patients With Proneural Glioblastoma May Derive Overall Survival Benefit From the Addition of Bevacizumab to First-Line Radiotherapy and Temozolomide: Retrospective Analysis of the AVAglio Trial. J Clin Oncol. 2015 Sep 1;33(25):2735-44. doi: 10.1200/JC0.2015.61.5005. Epub 2015 Jun 29. Erratum in: J Clin Oncol. 2016 Sep 1;34(25):3113. PMID: $26124478 ;$ PMCID: PMC5015426.

213. Park AK, Kim P, Ballester LY, Esquenazi Y, Zhao Z. Subtype-specific signaling pathways and genomic aberrations associated with prognosis of glioblastoma. Neuro Oncol. 2019 Jan 1;21(1):59-70. doi: 10.1093/neuonc/noy120. PMID: 30053126; PMCID: PMC6303485.

214. Karsy M, Gelbman M, Shah P, Balumbu O, Moy F, Arslan E. Established and emerging variants of glioblastoma multiforme: review of morphological and molecular features. Folia Neuropathol. 2012;50(4):301-21. doi: 10.5114/fn.2012.32361. PMID: 23319187.

215. Steponaitis G, Tamasauskas A. Mesenchymal and Proneural Subtypes of Glioblastoma Disclose Branching Based on GSC Associated Signature. Int J Mol Sci. 2021 May 7;22(9):4964. doi: 10.3390/ijms22094964. PMID: 34066996; PMCID: PMC8124327.

216. Behnan J, Finocchiaro G, Hanna G. The landscape of the mesenchymal signature in brain tumours. Brain. 2019 Apr 1;142(4):847-866. doi: 10.1093/brain/awz044. PMID: 30946477; PMCID: PMC6485274.

217. Fedele M, Cerchia L, Pegoraro S, Sgarra R, Manfioletti G. Proneural-Mesenchymal Transition: Phenotypic Plasticity to Acquire Multitherapy Resistance in Glioblastoma. Int J Mol Sci. 2019;20(11):2746. Published 2019 Jun 4. doi:10.3390/ijms20112746

218. Segerman A, Niklasson M, Haglund C, Bergström T, Jarvius $M, X i e ~ Y$, Westermark A, Sönmez D, Hermansson A, Kastemar M, Naimaie-Ali Z, Nyberg F, Berglund M, Sundström M, Hesselager G, Uhrbom L, Gustafsson M, Larsson R, Fryknäs M, Segerman B, Westermark B. Clonal Variation in Drug and Radiation Response among Glioma-Initiating Cells Is Linked to Proneural-Mesenchymal Transition. Cell Rep. 2016 Dec 13;17(11):2994-3009. doi: 10.1016/j.celrep.2016.11.056. PMID: 27974212. 
219. Inda MM, Bonavia R, Seoane J. Glioblastoma multiforme: a look inside its heterogeneous nature. Cancers (Basel). 2014;6(1):226-239. Published 2014 Jan 27. doi:10.3390/cancers6010226

220. Parker NR, Khong P, Parkinson JF, Howell VM, Wheeler HR. Molecular heterogeneity in glioblastoma: potential clinical implications. Front Oncol. 2015 Mar 3;5:55. doi: 10.3389/fonc.2015.00055. PMID: 25785247; PMCID: PMC4347445.

221. Becker AP, Sells BE, Haque SJ, Chakravarti A. Tumor Heterogeneity in Glioblastomas: From Light Microscopy to Molecular Pathology. Cancers (Basel). 2021;13(4):761. Published 2021 Feb 12. doi:10.3390/cancers 13040761

222. Paolillo M, Comincini S, Schinelli S. In Vitro Glioblastoma Models: A Journey into the Third Dimension. Cancers (Basel). 2021;13(10):2449. Published 2021 May 18. doi:10.3390/cancers 13102449

223. Jinan Behnan, Gaetano Finocchiaro, Gabi Hanna, The landscape of the mesenchymal signature in brain tumours, Brain, Volume 142, Issue 4, April 2019, Pages 847-866, https://doi.org/10.1093/brain/awz044

\section{Figures}




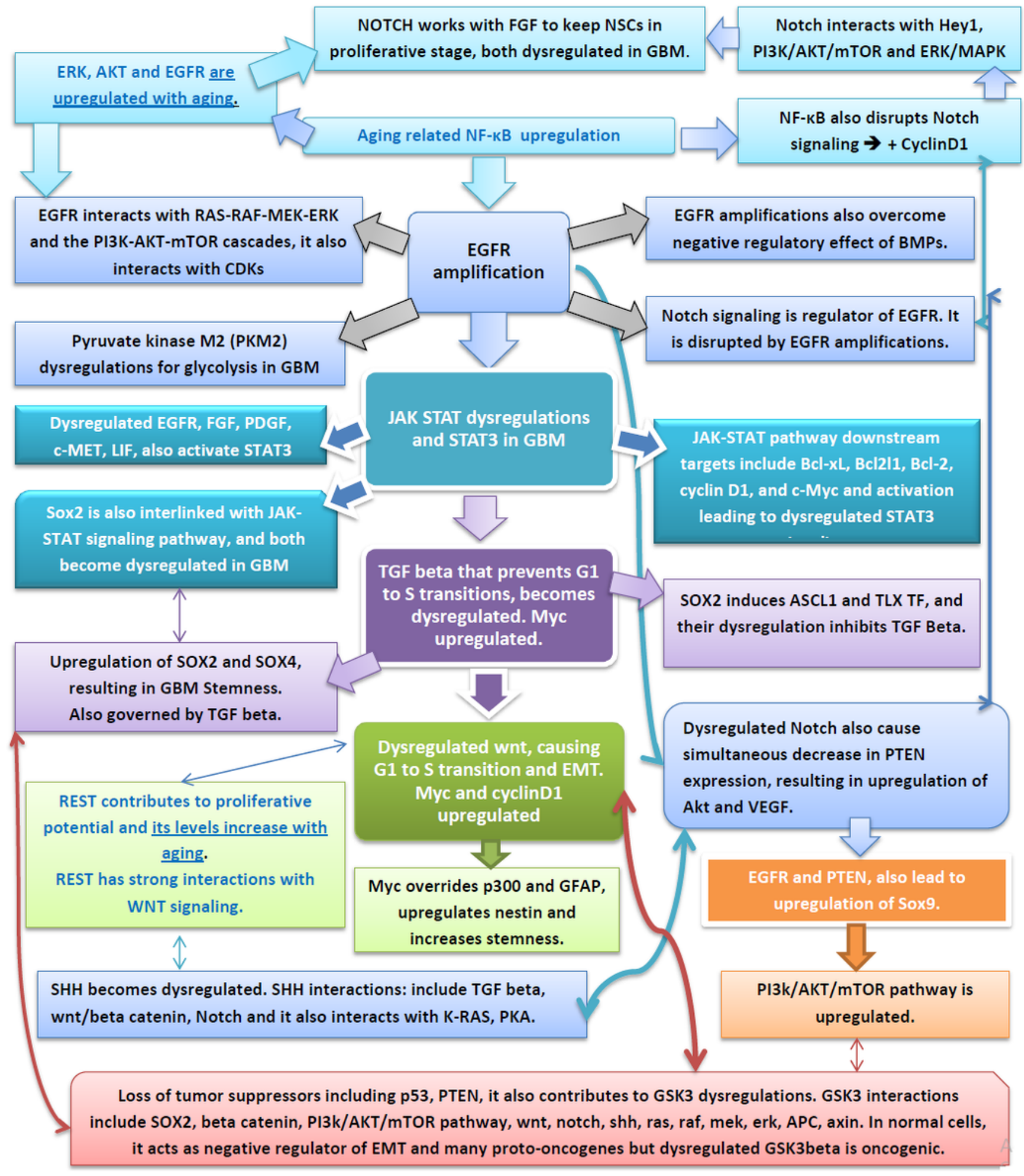

\section{Figure 1}

INTERCONNECTEDNESS OF GBM LANDSCAPE 


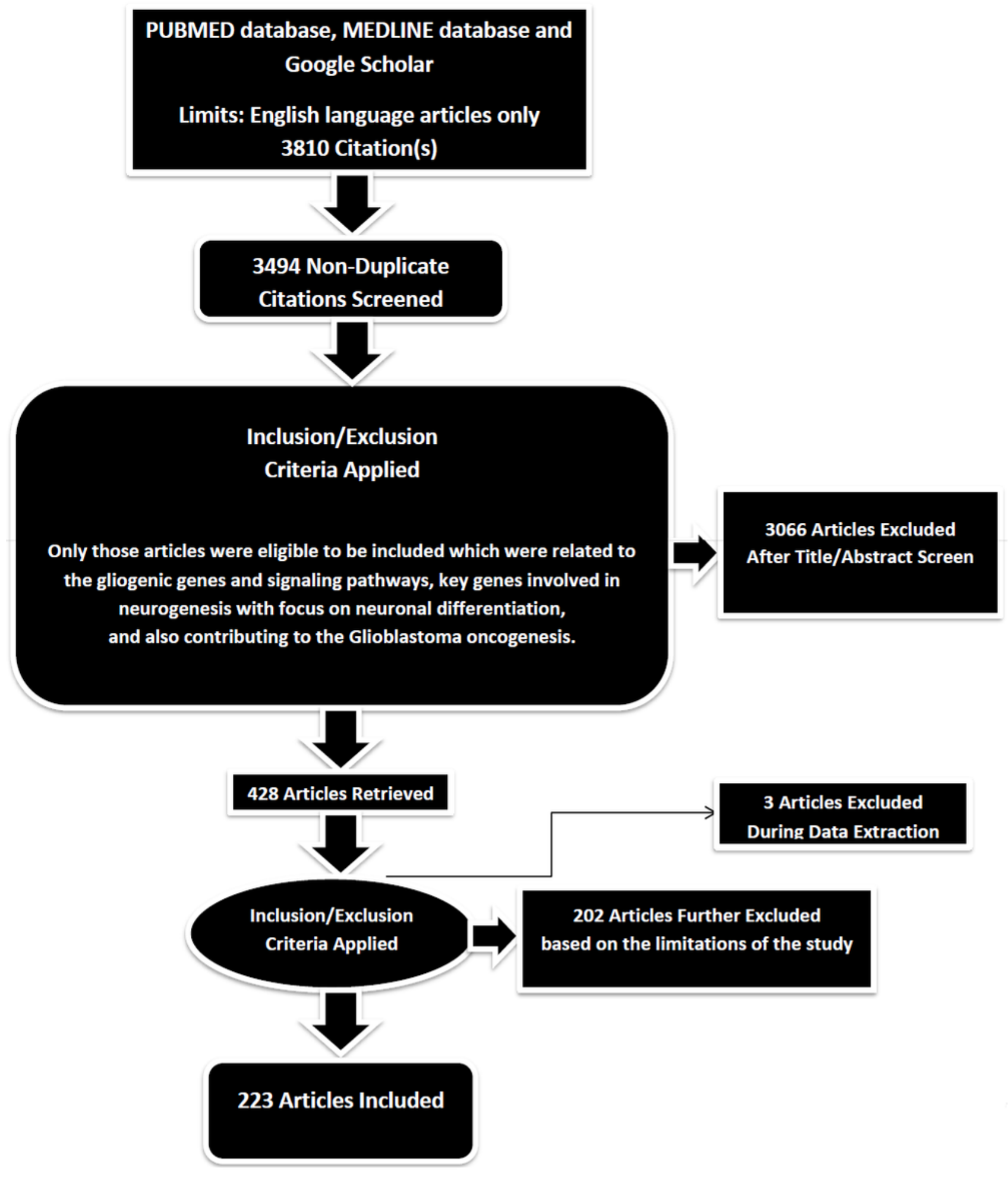

Figure 2

PRISMA Flow Diagram 